\title{
Itinerario de la categoría de sujeto político en el pensamiento de Ernesto Laclau
}

\author{
Itinerary of the category of political subject in the thought of Ernesto Laclau
}

\author{
Camilo Valdés Castillo*
}

\begin{abstract}
Resumen: Este artículo intenta establecer un itinerario de la categoría de sujeto político en la teoría de Ernesto Laclau. En un primer momento, desglosaremos la categoría de sujeto en la obra de Laclau y Mouffe, siguiendo la premisa foucaultiana de posiciones de sujeto. Sin embargo, esto cambiará a partir de la obra Nuevas reflexiones acerca de la revolución de nuestro tiempo dónde Laclau optará por analizar al sujeto como falta. En este sentido, es fundamental tener en cuenta la crítica de Slavoj Žižek a Hegemonía y estrategia socialista, ya que ella repercutirá luego en el movimiento categorial del sujeto planteado por Laclau. A partir de las nociones de identificación y decisión, el argentino sostendrá la constitución de identidades colectivas como sujetos descentrados en el campo político. En un segundo momento, Laclau expondrá la cuestión del sujeto desde la oposición entre agente social/estructura, según la cual hay sujeto como falta porque hay dislocación en la estructura, lo que le permitirá plantear la incapacidad de cierre en la identidad particular y social, de lo que se desprende su análisis en torno a la imposibilidad de lo social. En tercer momento, veremos cómo Laclau rechazará cualquier trascendencia del sujeto, rasgo propio de la modernidad, pues al no haber un sujeto político privilegiado, el espacio político queda abierto a la multiplicidad de identidades colectivas. En este sentido, las identidades colectivas en el espacio social están en relación con la emergencia de nuevos antagonismos sociales. Finalmente, y en un cuarto momento, se analizará la categoría de sujeto como pueblo a partir de la obra La razón populista, dónde la categoría de populismo será el eje central para comprender la lógica de formación de las identidades colectivas desde la teoría política de Laclau
\end{abstract}

Palabras claves: Laclau; sujeto político; hegemonía; identidades; pueblo

Abstract: This article tries to establish an itinerary of the category of political subject in the theory of Ernesto Laclau. At first, we will break down the category of subject in the work of Laclau and Mouffe, following the Foucaultian premise of subject positions. However, this will change from the work New thoughts on the revolution of our time where Laclau will choose to analyze the subject as a fault. In this sense, it is essential to take into account the criticism of Slavoj Žižek to Hegemony and socialist strategy, since it will later affect the categorial movement of the subject proposed by Laclau. From the notions of identification and decision, the Argentine will sustain the constitution of collective identities as decentralized subjects in the political field. In a second moment, Laclau will expose the question of the subject from the opposition between social agent / structure, according to which there is subject as a lack because there is dislocation in the

\footnotetext{
* Profesor de Filosofía y Licenciado en Educación de la Pontificia Universidad Católica de Valparaíso. Licenciado en Filosofía de la Pontificia Universidad Católica de Valparaíso. Artículos publicados: "La categoría de la hegemonía: antecedentes desde la tradición marxista hasta el postmarxismo de Laclau y Mouffe" (Revista de Filosofía Otro Siglo, 2017), "Hegemonía: aproximación a la constitución de sujetos políticos en Laclau" (Revista Internacional de Filosofía Mutatis Mutandis) y "Sensación y política en Gillles Deleuze” (Revista Aurora, 2017) en colaboración con el Dr. Ricardo Espinoza Lolas y Dr. Patricio Lombardo Bertolini.
} 
structure, which will allow him to pose the inability to close in the particular and social identity, from what emerges his analysis around the impossibility of the social. In the third moment, we will see how Laclau will reject any transcendence of the subject, characteristic of modernity, since there is no privileged political subject, the political space is open to the multiplicity of collective identities. In this sense, collective identities in the social space are related to the emergence of new social antagonisms. Finally, and in a fourth moment, the category of subject as a people will be analyzed from the work The populist reason, where the category of populism will be the central axis to understand the logic of formation of collective identities from the political theory of Laclau.

Key words: Laclau; political subject; hegemony; identities; people

Recibido: 5 agosto 2018 Aceptado: 7 octubre 2018

\section{Introducción}

La definición de las condiciones que permiten determinar la estructura de la subjetividad política se han presentado siempre como un problema para la filosofía y la teoría política contemporánea. En este contexto, Ernesto Laclau opta por desarrollar un andamiaje teórico que le permita hacerse cargo del problema desde distintos andamiajes teóricos. Cuando el filósofo argentino comienza a escribir sobre teoría política se puede observar claramente la gran influencia que tiene el marxismo en su andamiaje teórico. Sin embargo, no sólo el marxismo ocupa un lugar importante en su horizonte intelectual, sino también el postestructuralismo, la desconstrucción, el psicoanálisis, la fenomenología, la retórica y el postmarxismo. Así, no es de extrañar que Laclau recurra al pensamiento de intelectuales del siglo XX tan diversos, desde lo teórico y lo político, como Antonio Gramsci, Jacques Derrida o Jacques Lacan. Laclau sostiene en una entrevista: "yo creo que la historia intelectual del siglo XX empezó con tres ilusiones de absoluta inmediatez, que fueron: el referente, el fenómeno y el signo [...]. Éstas habían dado lugar a tres grandes tendencias: la filosofía analítica, la fenomenología y el estructuralismo". ${ }^{1}$ En Hegemonía y estrategia socialista, Laclau y Chantal Mouffe trazan una genealogía de la categoría de hegemonía ${ }^{2}$ en relación a la tradición marxista, postulando por primera vez el horizonte «post-marxista» como proyecto teórico y político para la izquierda, en torno a la idea de democracia radical. Para Laclau y Mouffe la transición del marxismo al post-marxismo no es sólo un cambio óntico, sino también ontológico. El enfoque que ellos proponen, privilegia la articulación política, y su categoría central para el análisis político es la de «hegemonía», y posteriormente, en Laclau será el «populismo».

${ }^{1}$ Laclau, Ernesto. "Post-marxismo, discurso y populismo". Mauro Cerbino, en: Revista Íconos, núm. 44, Quito, sept-dic, 2012, p. 130. Cfr. Laclau, Ernesto y Mouffe, Chantal. Hegemonía y estrategia socialista. Hacia una radicalización de la democracia, Buenos Aires, FCE, 2004, p. 11. Butler Judith, Laclau, Ernesto y Žižek, Slavoj. Contingencia, hegemonía y universalidad. Diálogos contemporáneos en la izquierda, Buenos Aires, FCE, 2003, p. 80.

2 La categoría de hegemonía desarrollada por Laclau ha sido criticada desde principios de la década de los ochenta por otros autores contemporáneos a él, quienes en general cuestionan la visión simplista, débil y distorsionada del marxismo que realiza Laclau. Cfr. Borón, Atilio y Cuéllar, Óscar. "Apuntes críticos sobre la concepción idealista de la hegemonía", en: Revista Mexicana de Sociología, Año XLV, vol. XLV, núm. 4, 1983, pp. 1143-1177; Borón, Atilio. "¿Posmarxismo? Crisis, recomposición o liquidación del marxismo en la obra de Ernesto Laclau”, en: Revista Mexicana de Sociología, México. vol. 58, núm. 1, 1996, pp. 1742; Rush, Alan. "Marxismo y Posmarxismo. Polémica Laclau-Mouffe/Geras", en: Revista Herramienta, núm. 18, 2003; Kohan, Néstor. "La herencia del fetichismo y el desafío de la hegemonía en una época de rebeldía generalizada", en: Revista Utopía y praxis latinoamericana. vol. 10, núm. 29, Universidad del Zulia, Venezuela, 2005, pp. 79-102; Veltmeyer, Henry. "El proyecto postmarxista: aporte y crítica a Ernesto Laclau”, en: Revista Theomai. Estudios sobre sociedad, naturaleza y desarrollo, núm. 14, 2006, pp. 1-15; entre otros. 
La obra de Laclau se establece en relación a dos enfoques teóricos. Por un lado, el pensamiento post-fundacional; ${ }^{3}$ por otro, la izquierda lacaniana. ${ }^{4}$ Este artículo se situará principalmente en la recepción de la obra de Laclau en un horizonte post-fundacional, sin embargo, también nos remitiremos a los usos que el filósofo argentino hace de los términos psicoanalíticos para abordar de manera más integra su andamiaje teórico. Desde la perspectiva de Marchart, el post-fundacionalismo tiene su raíz en los aportes extraídos tanto de la teoría post-estructuralista como psicoanalítica. El pensamiento político postfundacional reflexiona en torno a la diferencia conceptual entre «lo político»y «la política», en otras palabras, sobre cómo la «diferencia» asume el fundamento ausente de la sociedad.

En cuanto diferencia, ésta [teoría política] no presenta sino una escisión paradigmática en la idea tradicional de política, donde es preciso introducir un nuevo término (lo político) a fin de señalar la dimensión "ontológica" de la sociedad, la dimensión de la institución de la sociedad, en tanto que "política" se mantuvo como el término para designar las prácticas "ónticas" de la política convencional (los intentos plurales, particulares $y$, en última instancia, fallidos en fundar la sociedad). 5

Esto tiene como consecuencia que haya una preponderancia de «lo político» por sobre «lo social». Según Marchart, tal horizonte ha adquirido relevancia en la teoría política contemporánea a la hora de comprender distintos procesos en torno a la institución del orden social, la disputa y transformación a partir de los conflictos, y, asimismo, en torno a la constitución de identidades colectivas: vale decir, de los sujetos políticos. De este modo, el post-fundacionalismo no tiene que ser confundido con un antifundacionalismo, sino entenderse más bien como la imposibilidad de establecer un fundamento último para lo social. Este enfoque nos permite visualizar de forma más clara, los argumentos que presenta Laclau en relación a la «imposibilidad de la sociedad», en contraposición al racionalismo del marxismo clásico y a la lógica de la necesidad de la historia y de la sociedad como totalidad inteligible, rasgo que, según él, también se observa en la idea hegeliana de sociedad como un «conjunto estructurado complejo» ${ }^{6}$. De manera que, hay un énfasis en el carácter contingente de la política y de lo político como un momento fundante parcial, que nunca alcanza su clausura definitiva. Laclau comparte con el pensamiento postfundacional la pregunta por los modos de construcción del orden social como registro político. En este sentido, la claridad conceptual de Chantal Mouffe señala de forma precisa la diferencia de lo político y la política:

Si quisiéramos expresar dicha distinción de un modo filosófico, podríamos decir, tomando el vocabulario de Heidegger, que "la política" se refiere al nivel "óntico", mientras que "lo político" tiene que ver con el nivel "ontológico". Esto significa que lo óntico tiene que ver con la multitud de prácticas de la política convencional, mientras que lo ontológico tiene que ver con el modo mismos que se instituye la sociedad. ${ }^{7}$

La experiencia de la falta de un fundamento le permite a Laclau articular política y estratégicamente elementos divergentes y constituir nuevas identidades colectivas, esto se vislumbra claramente al inicio

\footnotetext{
3 Oliver Marchart ubica el pensamiento de Ernesto Laclau en el horizonte post-fundacionalista. Cfr. Marchart, Oliver. El pensamiento político posfundacional. La diferencia política en Nancy, Lefort, Badiou y Laclau. Buenos Aires, Fondo de Cultura Económica, 2009.

4 Tanto Yannis Stavrakakis como Jorge Alemán ubicarán el pensamiento de Laclau en torno a la denominada "izquierda lacaniana”. Cfr. Stavrakakis, Yannis. La izquierda lacaniana. Psicoanálisis, teoría y política. Buenos Aires, FCE, 2010. Alemán, Jorge. Para una irquierda lacaniana... Intervenciones y textos. Buenos Aires, Grama, 2009.

5 Marchart, Oliver. El pensamiento político posfundacional. La diferencia política en Nancy, Lefort, Badiou y Laclau. Buenos Aires, Fondo de Cultura Económica, 2009, p. 19. (el destacado es del original)

${ }_{6}^{6}$ Cfr. Retamozo, Martin. "Laclau y la dialéctica. Notas sobre un desencuentro con Hegel (y con Marx)", Izquierdas, 36, noviembre 2017, pp. 278-295.

${ }^{7}$ Mouffe, Chantal. En torno a lo político. Buenos Aires, FCE, 2011, pp. 15-16.
} 
de La razón populista, pues Laclau señala: "Este libro se interroga principalmente sobre la lógica de formación de identidades colectivas". 8

La relevancia del enfoque postestructuralista dejará dos marcas decisivas en el andamiaje teórico de Laclau: Por un lado, la importancia de la desconstrucción derridiana, a partir de la noción de «indecibilidad»; por otro lado, la teoría de Lacan, que le proveerá varias herramientas analíticas para la construcción de identidades colectivas. Como veremos más adelante, la categoría lacaniana de point de caption (punto nodal), y posteriormente, el objeto $a$. Este planteamiento nos permitirá desarrollar también nuestra propia hipótesis de trabajo respecto a la constitución de sujetos políticos, entendidos como procesos de subjetivación colectiva. En esta línea, creemos que la noción de sujeto es anterior a la subjetivación, pues se establece a partir de la categoría de «identificación». Ello quiere decir que el sujeto sólo puede constituirse como una identidad autodeterminada a través de actos de identificación. Así, con Laclau, estimamos que la identificación es una dimensión inherente a la decisión, lo que nos permitiría pensar los intercambios hegemónicos como dependientes de articulaciones políticas y no de entidades constituidas por fuera del terreno político. En este sentido, veremos cómo en La razón populista la categoría de «populismo» será el eje principal para analizar una lógica de formación de identidades populares a partir de diversos andamiajes teóricos como el postmarxsimo, el postfundacionalismo, el postestructuralismo, el psicoanálisis, la desconstrucción y la retórica.

Ahora bien, por un lado, tanto el psicoanálisis como la desconstrucción coindicen en que todo sistema, orden social o identidad, posee un rango de constitución abierta o, mejor, una indeterminación. Y por otro, el postfundacionalismo aborda cómo la diferencia asume el fundamento ausente de la sociedad. A partir de la dimensión política del sujeto nos surgen las siguientes preguntas: ¿Qué entiende Laclau como sujeto?, ¿Cómo se constituyen los sujetos políticos en la teoría de Laclau?, ¿Cuál es la relación entre la imposibilidad de la sociedad y las identidades colectivas?, ¿Es el populismo una herramienta analítica para comprender las identidades populares?

\section{Posiciones de sujeto}

Antes de entrar en el análisis de la constitución de sujetos políticos, comenzaremos abordando la categoría de sujeto, relacionada con la dualidad óntica/ontológica. Teniendo esto como punto de partida, es necesario aclarar que Laclau abordará los procesos de subjetivación respecto de la construcción de identidades colectivas no siempre con términos unívocos, sino que encontraremos en su desarrollo distintas formulaciones que refieren a las identidades colectivas: actores, agentes, sujetos, entre otras. Respecto a esto Martin Retamozo señala:

[...] Laclau emplea una variedad de formas de referirse a colectivos: sujeto, agente político populista, actores sociales, agente histórico, grupo dominado, subjetividad popular, entre otras, sin la precisión terminológica ni la claridad conceptual presente en otras partes de su obra y con pocas referencias al lugar en el que más avanza en una teoría de sujeto político. ${ }^{9}$

Ahora bien, este artículo pretende dar cuenta de cierto recorrido de la categoría de sujeto en la teoría política de Laclau, pero para ello, hay que advertir que nuestro análisis comienza con la obra de Laclau en conjunto con Chantal Mouffe en la obra Hegemonía y estrategia socialista.

Laclau y Mouffe en el tercer capítulo de Hegemonia y estrategia socialista: "Más allá de la positividad de lo social", plantean que la discusión en torno al sujeto tiene dos directrices: por un lado, el problema

\footnotetext{
8 Laclau, Ernesto. La razón populista. Buenos Aires, FCE, 2005, p. 9

9 Retamozo, Martin. "La teoría del populismo de Ernesto Laclau: una introducción”, en Estudios políticos, num. 41 (mayo-agosto), 2017, pp: 157-184, México, D. F, p. 176.
} 
relativo al carácter discursivo o pre-discursivo del sujeto; y, por otro lado, al tipo de relación existente entre las distintas posiciones del sujeto. ${ }^{10}$ Laclau y Mouffe nos dirán:

\begin{abstract}
El mundo objetivo se estructura en secuencias relacionales que no tienen un sentido finalístico y que, en verdad, en la mayor parte de los casos, tampoco requieren ningún sentido precisable: basta que ciertas regularidades establezcan posiciones diferenciales para que podamos hablar de una formación discursiva. Dos importantes consecuencias se siguen de esto: la primera, que la materialidad del discurso no puede encontrar el momento de su unidad en la experiencia o conciencia de un sujeto fundante, ya que el discurso tiene una existencia objetiva y no subjetiva.; por el contrario, diversas posiciones de sujeto aparecen dispersas en el interior de una formación discursiva. La segunda consecuencia es que la práctica de la articulación fijación/dislocación de un sistema de diferencias tampoco puede consistir en meros fenómenos lingüístico, sino que debe atravesar todo el espesor material de instituciones, rituales, prácticas de diversos orden, a través de las cuales una formación discursiva se estructura. ${ }^{11}$
\end{abstract}

Siguiendo esto, el primer problema se refiere al cuestionamiento creciente de la «constitutividad» subjetiva, y agregan que esta problemática ha sido atribuida a «individuos humanos» tanto desde una perspectiva empirista como racionalista, en tres formas:

[...] la crítica a una concepción del sujeto que hace de él un agente racional y transparente a sí mismo; la crítica a la supuesta unidad y homogeneidad entre el conjunto de sus posiciones, y la crítica a la concepción que ve en él el origen y fundamento de las relaciones sociales (el problema de la constitutividad en sentido estricto). ${ }^{12}$

Laclau y Mouffe recurren a la «analítica de la finitud» foucaultiana, que se debate en un conjunto de oposiciones: los dualismos empírico/trascendental; cogito/impensado; la retirada/retorno del origen; todo ellos "insuperables en la medida en que se mantenga la categoría de 'Hombre' como sujeto unificado". ${ }^{13} \mathrm{El}$ gran problema consiste en romper con la categoría de «sujeto originario». ${ }^{14}$ En virtud de ello, los autores se alejan de esta concepción moderna, y utilizan la categoría de sujeto como "posiciones de sujeto» al interior de la estructura discursiva: significantes susceptibles de ser articulados en diversas formaciones discursivas, necesariamente abiertas. Laclau y Mouffe rechazan así que los sujetos sean el origen de las relaciones sociales, pues toda «experiencia» dependería de las condiciones discursivas de posibilidad precisas, en palabras de los autores: "Si toda posición de sujeto es una posición discursiva, el análisis no puede prescindir de las formas de sobredeterminación de unas posiciones por otra - del carácter contingente de toda necesidad que, según hemos visto, es inherente a toda diferencia discursiva$" .15$

Es decir, toda posición de sujeto es una posición discursiva. Por consiguiente, el carácter abierto del discurso impide que se fijen totalmente las posiciones de sujeto en un sistema cerrado de diferencias. De manera que los autores afirman el carácter abierto del discurso respecto de las posiciones de sujeto, en rechazo a la noción de sujeto como totalidad originaria y fundante.

10 Posiciones de sujeto es un término empleado por Michel Foucault. Cfr. "La formación de las modalidades enunciativas", pp. 69-76, en: Foucault, Michel. La arqueología del saber. Buenos Aires, SigloXXI, 2015.

${ }^{11}$ Laclau, Ernesto y Mouffe, Chantal. Hegemonia y estrategia socialista. Hacia una radicalización de la democracia. Buenos Aires, FCE, 2004, p. 148

12 Ibíd., p. 155.

13 Ibíd., p.156.

14 Cfr. Marchart, Oliver. El pensamiento politico posfundacional: la diferencia politica en Nancy, Lefort, Badiou y Laclau. Buenos Aires, FCE, 2009.

15 Laclau, Ernesto y Mouffe, Chantal. Hegemonía y estrategia socialista. Hacia una radicalización de la democracia. Buenos Aires, FCE, 2004, pp. 156-57. 
A partir de esto, señalarán las diversas formas en la que la sobredeterminación de los sujetos sociales y políticos ha sido considerada por la tradición marxista. Según esto, el punto de partida es bastante claro: [...] los sujetos son las clases sociales, cuya unidad se constituye en torno a intereses determinados por su posición en las relaciones de producción Sin embargo, más importante que insistir en este tema común es estudiar las formas precisas en que el marxismo ha respondido teórica y políticamente a la diversificación y dispersión de sujetos de los agentes clasistas respecto de las que hubieran debido ser las formas paradigmáticas de su unidad. ${ }^{16}$

En este aspecto, indican la ilegitimidad en que se funda la tradición marxista, al afirmar que la lucha política y económica de los obreros está unificada por el agente social preconstituido, es decir, la clase obrera. Según los autores, la expresión «clase obrera» es utilizada de dos modos distintos: por un lado, para definir una posición específica de sujeto en las relaciones de producción; y, por otro, para nombrar a los agentes que ocupan esa posición de sujeto. Este supuesto implícito de unidad y transparencia de todo agente contribuye a consolidar la confusión. Pero esto se utiliza sólo cuando se trata de afirmar la unidad entre posiciones empíricamente dadas, no cuando se trata de explicar la esencial heterogeneidad de unas posiciones respecto de otras. En el caso de la tradición marxista, la unidad de clase es concebida como unidad futura, con lo cual la forma de esa unidad se funda en la categoría de «representación»; es decir, la escisión entre los obreros reales y sus intereses objetivos exigen la representación por parte del partido de vanguardia desde el leninismo (no así en el maoísmo). En efecto, es necesario aclarar que cuando Laclau y Mouffe refieren a la representación, ellos señalan tajantemente que toda representación se funda en una ficción, en la presencia de algo que está ausente en sí mismo, en sus palabras: [...] toda relación de representación se funda en una ficción: la de la presencia a un cierto nivel de algo que, estrictamente, está ausente del mismo. Pero por el hecho mismo de que se trata a la veź de una ficción y de un principio organizado de ciertas relaciones sociales, la representación es el terreno de un juego cuyo resultado no está predeterminado desde el comienzo. ${ }^{17}$

$\mathrm{Al}$ ser la representación una ficción, y, asimismo, un principio organizador de ciertas relaciones sociales. Siguiendo a Oliver Marchart, en Laclau la relación de representación tiene que ser diferenciada entre el contenido óntico de lo representado y la función ontológica del principio de representatividad como tal. Así, dirá Laclau: "Si la repetición [representación] se torna posible/imposible por una falta primordial, ningún contenido óntico puede en última instancia monopolizar la función ontológica de representar la representabilidad como tal". ${ }^{18}$

En Hegemonía y estrategia socialista, Laclau y Mouffe exponen un ejemplo de representación basada en la concepción marxista del partido de vanguardia. Según esto, el partido no representa a un agente concreto, sino a sus intereses históricos, por lo que no habría ficción en tanto el discurso constituye desde el mismo horizonte al representado y representante. Sin embargo, esto sólo sería posible si la práctica política fuese un campo perfectamente delimitado, lo que significaría excluir por principio toda sobredeterminación de la representación y esto sólo lo admite una concepción esencialista. Así, la relación de articulación no es una relación de necesidad, porque si la dispersión de las posiciones de sujeto es una condición para la práctica articulatoria, esa dispersión no tiene por qué adoptar la forma de una separación entre la identidad política y la identidad económica de los agentes sociales. ${ }^{19}$ Cuando se sutura al sujeto (identidad política y económica de los agentes sociales) hay una relación tautológica, en la cual representante y representado constituyen momentos de una identidad colectiva única. De esta manera, al contrario de la concepción marxista del partido de vanguardia, Laclau y Mouffe señalan que "ni la identidad política ni la identidad económica de los agentes sociales cristaliza en momentos de un discurso

\footnotetext{
16 Ibíd., p. 160.

${ }^{17}$ Laclau, Ernesto y Mouffe, Chantal. Hegemonía y estrategia socialista. Hacia una radicalización de la democracia, Buenos Aires, FCE, 2004, p. 161

18 Laclau, Ernesto. "Identidad y hegemonía”, en: Butler Judith, Laclau, Ernesto y Žižek, Slavoj. Contingencia, hegemonía y universalidad. Diálogos contemporáneos en la izquierda. Buenos Aires, FCE, 2003, p. 77.

${ }^{19}$ Ibíd., p. 163.
} 
unificado, sino que la relación entre ambos es la unidad precaria de una tensión". ${ }^{20}$ De aquí surge la subversión de cada uno de los términos en una polisemia que impide su articulación: en este caso, lo económico está y no está en lo político, y viceversa. Tal relación no es de diferenciaciones literales, sino de analogías inestables entre dos términos, pues se trata de una fictio iuris (ficción legal) de la representación. Según Laclau y Mouffe:

La representación se constituye, por tanto, no como un tipo definido de relación, sino como el campo de una oscilación inestable cuyos puntos de fuga son, según hemos visto, o bien la literalización de la ficción a través del corte de todo lazo entre representante y representado, o bien la desaparición de la identidad separada de ambos a través de su absorción como momentos de una identidad única. ${ }^{21}$

Ésta se constituye así, como el campo de una oscilación inestable, cuyos puntos de salida son la literalización de una ficción, por un lado, a través de la rotura de todo lazo entre representante y representado y, por otro, la desaparición de la identidad separada de ambos, absorbidos como momentos de una identidad única, por lo que una representación nunca logrará una plenitud total.

Según ambos: "la especificidad de la categoría de sujeto no puede establecerse ni a través de la absolutización de una dispersión de 'posiciones de sujeto', ni a través de la unificación igualmente absolutista en torno a un 'sujeto trascendental"'. ${ }^{22}$ La categoría de sujeto estaría impregnada así de un carácter polisémico, ambiguo e incompleto, que la sobredeterminación acuerda a toda identidad discursiva. En relación a esto, señalarán:

[...] el momento de cierre de una totalidad discursiva, que no es dado a nivel "objetivo" de dicha totalidad, tampoco puede ser dado al nivel de un sujeto que es "fuente de sentido", ya que la subjetividad del agente está penetrada por la misma precariedad y ausencia de sutura que cualquier otro punto de la totalidad discursiva de la que es parte. "Objetivismo" y "subjetivismo"; "totalitarismo" e "individualismo" son expresiones simétricas del deseo de una plenitud que es permanentemente diferida". ${ }^{23}$

Esa misma falta de una sutura última impide que la dispersión de posiciones de sujeto constituya una posible solución, pues ninguna de las ellas logra consolidarse como posición clausurada. Nuevamente, hay un juego de sobredeterminación en la que se introduce el horizonte de una totalidad imposible, lo que permite, precisamente, la articulación hegemónica. ${ }^{24}$

Laclau y Mouffe entenderán la imposibilidad de cierre como «la imposibilidad de la sociedad», ${ }^{25}$ dada la precariedad de toda identidad que se muestra como movimiento continuo de diferencias. En este contexto los autores introducen la categoría de «antagonismo». Ella se refiere a la «experiencia» del límite de la «objetividad», ${ }^{26}$ es decir, a la condición de posibilidad de todo límite de la sociedad, y, asimismo, a la imposibilidad de lo social de constituirse plenamente. La relación que estableceremos entre las categorías de hegemonía y antagonismo es tal en la medida que el antagonismo posibilita la articulación

\footnotetext{
${ }^{20}$ Laclau, Ernesto y Mouffe, Chantal. Hegemonía y estrategia socialista. Hacia una radicalización de la democracia. Buenos Aires, FCE, 2004, p. 163.

21 Ibíd., 163.

22 Ídem.

23 Ibíd., p. 164.

24 Más adelante, veremos cómo Laclau reconsiderará la noción de sujeto a partir de Nuevas Reflexiones acerca de la Revolución de nuestro tiempo, y en la que podremos apreciar la especificidad del pensamiento laclausiano respecto al de Chantal Mouffe.

25 Laclau tiene un texto que aparece en Nuevas reflexiones acerca de la revolución de nuestro tiempo que aborda esto, aparecido por primera vez en inglés como "The imposibility of society", en: Canadian Journal of Political and Social Theory, vol. 7 núm. 1 y 2, HiverPrintemps, 1983.

${ }^{26}$ Laclau, Ernesto y Mouffe, Chantal. Hegemonía y estrategia socialista. Hacia una radicalización de la democracia. Buenos Aires, FCE, 2004, p. 164.
} 
hegemónica y, por ende, permite rechazar así una sociedad suturada como unidad sin fisuras. Según los autores:

El antagonismo, por tanto, lejos de ser una relación objetiva, es una relación en la que se muestran -en el sentido en que Wittgenstein decía que lo que no se puede decir se puede mostrar- los límites de toda objetividad. Pero si, como hemos visto, lo social sólo existe como esfuerzo parcial por instituir la sociedad -esto es, un sistema objetivo y cerrado de diferencias- el antagonismo, como testigo de la imposibilidad de una sutura última, es la "experiencia" del límite de lo social. Estrictamente hablando, los antagonismos no son interiores sino exteriores a la sociedad; o, mejor dicho, ellos establecen los límites de la sociedad, la imposibilidad de esta última de constituirse plenamente. ${ }^{27}$

Lo social como espacio no puede ser suturado, y por eso la experiencia del límite de lo social debe considerarse desde dos aspectos diferentes:

Por un lado, como experiencia de fracaso. Si el sujeto es construido a través del lenguaje, como incorporación parcial y metafórica a un orden simbólico, toda puesta en cuestión de dicho orden debe constituir necesariamente una crisis de identidad. Pero, por otro lado, esta experiencia del fracaso no es el acceso al orden ontológico diverso, a un más allá de las diferencias, simplemente porque no hay más allá. ${ }^{28}$

El límite de lo social al interior mismo de lo social niega la aspiración de la experiencia a constituirse en una presencia plena. La sociedad no puede suturarse debido a que todo en ella está atravesado por sus propios límites, que le impiden constituirse como una realidad objetiva.

En este punto, es necesario advertir que, respecto de la categoría de sujeto abordada por Laclau y Mouffe, el análisis que se expone en Hegemonía y estrategia socialista tiene un marcado énfasis en la lógica del significante y las posiciones de sujeto, que les permiten rechazar los presupuestos esencialistas de lo social como totalidad suturada. Sin embargo, su abordaje teórico se limita sólo a establecer conceptos funcionales a las posiciones de sujeto respecto de las concepciones de sujeto como origen de las relaciones sociales, como sujeto universal o como sujeto racional y homogéneo. La categoría de sujeto que proponen es elaborada a partir de la tensión precaria que comparten las identidades discursivas, donde el sujeto es relegado a una dispersión de posiciones de sujeto que reduce el espacio subjetivo en la práctica discursiva. $\mathrm{Al}$ desligarse Laclau de una concepción esencialista del sujeto, anclada por ejemplo en el cogito cartesiano (que atravesó la filosofía política moderna), sostiene que no hay en realidad un sujeto, sino de posiciones de sujeto propagados al interior de una estructura.

En el prefacio a Nuevas reflexiones sobre la revolución de nuestro tiempo (1990), Laclau comenta cómo Slavoj Žižek contribuyó en su ideario a través de una incisiva crítica al tratamiento hecho a la categoría de sujeto. Señala Žižek sobre esto:

Su argumentación se dirige básicamente a atacar a la clásica noción del sujeto como una entidad sustancial y esencial, dada de antemano, que domina la totalidad del proceso social y que no es producida por la contingencia del propio proceso discursivo: contra ésta noción ellos afirman que lo que tenemos es una serie de posiciones particulares de sujeto (feminista, ecologista, democrática...) cuya significación no está fijada a priori: ellas cambian según el modo en que aquéllas son articuladas en una serie de equivalencias a través del excedente metafórico que define la identidad de cada una de esas posiciones. ${ }^{29}$

\footnotetext{
27 Ibíd., p. 169. (el destacado es del original)

28 Ibíd., p. 170.

${ }^{29}$ Respecto de la crítica de Žižek a Laclau y Mouffe en relación al sujeto, hay que señalar que Laclau al escribir Nuevas reflexiones acerca de la revolución de nuestro tiempo ya había leído el artículo del filósofo esloveno, pues este se publicó por primera vez en la edición inglesa original, por la editorial Verso de Londres en 1990. Žižek, Slavoj. "Más allá del análisis del discurso", en: Laclau, Ernesto. Nuevas reflexiones acerca de la revolución de nuestro tiempo. Buenos Aires, Nueva Visión, 2000, p. 258.
} 
Del mismo modo, el esloveno señala que la teoría del Real lacaniano ${ }^{30}$ opera en la noción de antagonismo desarrollada por Laclau y Mouffe en Hegemonía y estrategia socialista respecto del «antagonismo social», y especialmente en lo que se refiere el status del sujeto en el campo social estructurado a la luz de la imposibilidad central.

El real logro de Hegemonía se cristaliza en el concepto de "antagonismo social": lejos de reducir toda realidad a una suerte de juego del lenguaje, el campo socio-simbólico es concebido como estructurado en torno de una cierta traumática imposibilidad, en torno de una fisura que no puede ser simbolizada. En breve, Laclau y Mouffe, han reinventado, por así decirlo, la noción de lo real como imposible, ellos han trasformado a este último en una herramienta útil para el análisis social e ideológico. ${ }^{31}$

Siguiendo a Paula Biglieri y Gloría Perelló, lo relevante de la crítica de Žižek es que señala al antagonismo como un efecto de lo real en lo imaginario. En palabras de las autoras:

Estamos en el momento del énfasis imaginario de Laclau, es decir, aquel en el cual el antagonismo es problematizado en términos imaginarios. Recordemos que -para Lacan- lo imaginario en primer término se define como el lugar del yo por excelencia, [...] El registro imaginario tiene que ver esencialmente con la imagen, con la representación (en tanto lo que se vuelve a presentar en lugar de una ausencia), con el intento de síntesis, de unificación, de cierre de sentido. ${ }^{32}$

Ahora bien, por otro lado, Retamozo sostiene que la teoría del sujeto de Laclau avanza considerablemente en Nuevas reflexiones sobre la revolución de nuestro tiempo, y postula que las nociones fundamentales para pensar la conformación del sujeto son: antagonismo, decisión, mito e imaginario. 33 Volviendo a Laclau, el antagonismo, al ser el límite de toda objetividad, no expresa mi identidad sino la imposibilidad de constituirla. Porque las identidades se constituyen a través de su relación con lo/el otro. La sola presencia del otro me impide ser yo mismo, por ende, el antagonismo representa la precariedad misma de la identidad, la imposibilidad de su plenitud.

En Nuevas reflexiones sobre la revolución de nuestro tiempo Laclau va a radicalizar su concepción de antagonismo, pasando de las posiciones de sujeto foucaultianas al «sujeto como falta». ${ }^{34}$ En este sentido, vemos como Laclau acoge la crítica de Žižek, en torno al resultado de procesos de «identificación» ${ }^{35}$ desatados por esa falta de identidad originaria llamada «sujeto». En este sentido, la subjetivación es el momento de la identificación con una cierta estructura. ${ }^{36}$ Y agregaremos: "Como dice Kierkegaard, citado por Derrida: 'el momento de la decisión es el momento de la locura'. Y como yo [Laclau] agregaría (lo

${ }^{30}$ Glynos, Jason y Stavrakakis, Yannis. "Encuentros del tipo real. Indagando los límites de la adopción de Lacan por parte de Laclau", en: Critchley, Simon y Marchart, Oliver. Laclau. Aproximaciones críticas a su obra. Buenos Aires, FCE, 2008, p. 253.

31 Ibíd., p. 257.

32 Biblieri, Paula y Perelló, Gloria. Los usos del psicoanálisis en la teoría de la hegemonía de Ermesto Laclau. Buenos Aires, Grama, 2012. pp. $44-45$.

33 Retamozo, Martín. "Populismo en América Latina: desde la teoría hacia el análisis político. Discurso, sujeto e inclusión en el caso argentino", en: Revista Colombia Internacional, Universidad de Los Andes de Colombia, núm. 82, sept-dic, 2014 , p. 235.

34 Glynos, Jason y Stavrakakis, Yannis. "Encuentros del tipo real. Indagando los límites de la adopción de Lacan por parte de Laclau", en: Critchley, Simon y Marchart, Oliver. Laclau. Aproximaciones críticas a su obra. Buenos Aires, FCE, 2008, p. 250.

35 Jean Laplanche y Jean-Bertrand Pontalis nos entregan desde una matriz freudiana una definición de identificación: "Proceso psicológico mediante el cual un sujeto asimila un aspecto, una propiedad, un atributo de otro y se transforma, total o parcialmente, sobre el modelo de éste. La personalidad se constituye y se diferencia mediante una serie de identificaciones". Laplanche, Jean y Pontalis, Jean-Bertrand. Diccionario de psicoanálisis. Buenos Aires, Paidós, 2004, p. 184.

36 Laclau abordará el sujeto de la falta a través de los planteamientos del sujeto lacaniano a partir del estadio del espejo que desarrolla Lacan en sus primeros escritos. Cfr. Lacan, Jacques. Escritos. Tomo I, Buenos Aires, Siglo XXI, 1985. Desde la perspectiva de José Allevi, "El proceso de subjetivación articula las distintas identificaciones que pueden darse, pero cabe destacar que toda identificación implica un grado de agenciamiento propio del estatus del sujeto". Allevi, José. "Subjetividades, lo político y la política: Derivas de una discusión teórica”, en: Revista Athenea Digital, 15 (3), 2015, p. 153. 
que no haría Derrida): ése es el momento del sujeto antes de la subjetivación". ${ }^{37}$ Para Laclau, este es el momento donde se funda todo análisis político y social, pues la decisión implica una escisión entre lo ontológico y lo óntico:

[...] toda decisión está internamente escindida: es, por un lado, esa decisión (un contenido ontológico preciso), pero, por otro lado, es una decisión (tiene una función ontológica de proveer un cierto cierre a lo que estaba estructuralmente abierto). El punto crucial es que el contenido óntico no puede derivarse de la función ontológica, y entonces el primero será sólo una encarnación transitoria de la última. ${ }^{38}$

Como veremos luego, esto tiene implicancias respecto de la constitución de las identidades colectivas, como de la imposibilidad de la sociedad. En Nuevas reflexiones sobre la revolución de nuestro tiempo, Laclau introduce a partir del antagonismo la categoría de «dislocación». La dislocación se refiere a la incapacidad de establecer una fijación definitiva de la identidad y del orden social, pues depende de un exterior que, asimismo, niega la posibilidad de conformarse como identidad estable. De tal modo, la categoría de sujeto en Laclau toma aquí su especificidad respecto de la desarrollada junto a Mouffe en Hegemonía y estrategia socialista. Recordemos que las identidades son antagónicas, y que los agentes sociales no se constituyen plenamente a partir de la exterioridad de los unos con los otros, sino más bien dependen siempre de la constitución a partir de un Otro exterior, sin cierre. Es así que Laclau aborda la cuestión del sujeto desde la oposición entre agente social/estructura, según la cual hay sujeto como falta porque hay dislocación en la estructura:

La dislocación es la fuente de la libertad. Pero esta no es la libertad de un sujeto que tiene una identidad positiva -pues en tal caso sería tan sólo una posición estructural- sino la libertad derivada de una falla estructural, por lo que el sujeto sólo puede construirse una identidad a través de actos de identificación. ${ }^{39}$

Al estar la estructura dislocada, ésta «falla» permite que no haya determinaciones de orden estructural para el sujeto, evidenciando que él se autodetermina parcialmente. Sin embargo, como autodeterminación no es un sujeto que «ya»es, sino que, en su reverso, es consecuencia de su falta de ser, y como tal la identidad es posible sólo a través de «actos de identificación». Laclau sostendrá así que la identificación es una dimensión inherente a la decisión. ${ }^{40}$ Yannis Stavrakakis señala que la identificación no es ni una constitución, ni un proceso univoco o único. Desde su perspectiva, allí radica uno de los aportes centrales de la teoría lacaniana para el análisis político contemporáneo:

Un sujeto que por ser esencialmente dividido y alienado se convierte en el locus de una imposible identidad, el lugar donde se produce una entera política de identificación. Este sujeto es considerado generalmente como la mayor contribución de Lacan a la teoría contemporánea y al análisis político. ${ }^{41}$

Debido a esto: si hay necesidad de identificación es debido a que no hay identidad plena. Según Biglieri y Perelló, el lugar del sujeto está en relación con el momento de la decisión (identificación), y por ende, va más allá de la estructura; además, según ellas, Laclau abandonará la noción de posiciones de

\footnotetext{
37 Butler Judith, Laclau, Ernesto y Žižek, Slavoj. Contingencia, hegemonía y universalidad. Diálogos contemporáneos en la izquierda. Buenos Aires, FCE, 2003, p. 85.

38 Ibíd., pp. 85-86.

39 Laclau, Ernesto. Nuevas reflexiones acerca de la revolución de nuestro tiempo. Buenos Aires, Nueva Visión, 2000, p. 76.

40 Laclau, Ernesto. "Desconstrucción, pragmatismo, hegemonía”, en: Laclau, Ernesto, Rorty, Richard, Critchley, Simon y Derrida, Jacques. Mouffe, Chantal (comp.) Desconstrucción y pragmatismo. Buenos Aires, Paidós, 1998, p. 115.

${ }^{41}$ Stavrakakys, Yannis. Lacan y lo político. Buenos Aires, Prometeo, 2007, p. 31. (el destacado es del original)
} 
sujeto, con lo cual, todo rasgo de identidad positiva sólo puede establecer procesos de identificación. ${ }^{42}$ En Emancipación y diferencia Laclau afirmará la emergencia del sujeto como resultado del colapso de la objetividad. ${ }^{43}$ Ahora bien, si anteriormente se expuso que Laclau sostiene que la dislocación es la fuente de la libertad, donde la identidad se constituye a través de actos de identificación, ello nos permite ir pensando en la constitución de sujetos políticos a partir de los binarismos que surgen de la oposición sujeto/estructura.

\section{La cuestión de la oposición del sujeto y la estructura en Laclau}

Antes de introducirnos en las lógicas de formación de identidades colectivas, es necesario tener presente aquí la cuestión de la oposición entre agente social/estructura que desarrolla Laclau en "Imaginario social y revolución democrática" del libro Nuevas reflexiones acerca de la revolución de nuestro tiempo. Respecto a ello el argentino señalará cuatros dimensiones básicas de la relación antitética entre sujeto y estructura. En primer lugar, señala que «todo sujeto es un sujeto mítico».44 $\mathrm{El}$ mito es un espacio de representación que no se relaciona con ninguna objetividad estructural dominante, donde la condición objetiva de la emergencia del mito permite la dislocación estructural, pues su finalidad es suturar lo dislocado a través de un nuevo espacio de representación (una representación esencialmente hegemónica). En palabras de Laclau: "El momento de la realización del mito es, pues, el momento del eclipse del sujeto y de su reabsorción por la estructura [...] mediación que no es, en consecuencia, ella misma representable, ya que carece de espacio propio". ${ }^{45}$ De ahí que toda objetividad es un mito cristalizado, y su realización es el momento donde el sujeto es reducido a una posición de sujeto, es decir: el sujeto es sólo sujeto en tanto mediación de ambos espacios.

En segundo lugar, «el sujeto es, constitutivamente, metáfora». ${ }^{46}$ Laclau señala que el espacio mítico es un espacio dislocado, donde el sujeto no se constituye de forma lógica, Laclau nos dirá: "El carácter metafórico del espacio mítico procede, [...], de que el contenido concreto o literal del mito representa algo distinto de sí mismo: el propio principio de una literalidad plenamente alcanzada". ${ }^{47}$ Este espacio emergería debido a que se constituye como una crítica a la falta de estructuración del orden dominante. El carácter metafórico del espacio mítico es el contenido literal del mito que representa algo distinto de sí mismo. En otras palabras, el mito en tanto metáfora emerge solamente entre la dialéctica de la ausencia/presencia: en el primer caso, se refiere a la dislocación de la estructura; y en el segundo, a la identificación con una plenitud no alcanzada. Tal espacio será el espacio del sujeto, donde sólo adquiere su forma específica de representación como metáfora de una estructura ausente, Laclau señala: "El sujeto (falta en el interior de la estructura) sólo adquiere su forma específica de representación cómo metáfora de una estructuralidad ausente". 48

En tercer lugar, Laclau señala que «las formas de identificación del sujeto funcionan como superficies de inscripción». ${ }^{49} \mathrm{Si}$ entendemos al sujeto como metáfora de una plenitud, el contenido literal de sus formas de identificación funcionará como una representación misma de la plenitud. Así, una vez que las formas de identificación que le dan al sujeto existencia discursiva (el mito) han alcanzado una cierta vigencia social, la identificación será la inversión de la representación como dislocación de la

42 Biblieri, Paula y Perelló, Gloria. Los usos del psicoanálisis en la teoría de la hegemonía de Ernesto Laclau. Buenos Aires, Grama, 2012. p. 48.

${ }^{43}$ Cfr. Palti, Elías. "El retorno del sujeto. Subjetividad, historia y contingencia en el pensamiento moderno", en: Prismas. Revista de historial intelectual, núm. 7, 2003, pp. 27-50.

44 Laclau, Ernesto. Nuevas reflexiones acerca de la revolución de nuestro tiempo. Buenos Aires, Nueva Visión, 2000, p. 77.

45 Ídem.

46 Ídem.

47 Ibíd., p. 78

48 Ibíd., p.79.

49 Ídem. 
estructura, es decir: el mito funcionará como superficie de inscripción de dislocaciones y reivindicaciones sociales. Laclau señala:

El rasgo central de algo que se presenta como superficie de inscripción en su carácter incompleto: si el proceso de inscripción estuviera concluido, en tal caso entre la superficie y lo inscrito en ella habría una simetría esencial que borraría toda distancia entre expresión y lo expresado, pero si el proceso de inscripción nunca concluye, en tal caso esta simetría se rompe y nuestra mirada se desplaza al proceso mismo de inscripción. ${ }^{50}$

Por lo cual, la superficie de inscripción tendrá así siempre un carácter incompleto; por ello los mitos sociales son en tal sentido incompletos, pues su contenido se reconstituye y desplaza constantemente.

Finalmente, en cuarto lugar, «el carácter incompleto de las superficies míticas es la condición de posibilidad de constitución de los imaginarios sociales».51 Según Laclau: [...] la relación entre la inscripción y lo inscrito en ella siempre es, [...], esencialmente inestable" 52 . A partir de esto se señalan dos posibilidades extremas, por un lado, la completa hegemonización de la superficie, y por otro lado, que el momento de la representación logra una plenitud, que se constituiría en un horizonte ilimitado de inscripciones, y por ende, de toda dislocación posible. El imaginario es un horizonte, no un objeto más entre los objetos, sino un límite absoluto que estructura el campo de lo inteligible en tanto condición de posibilidad de emergencia de todo objeto $\mathrm{El}$ autor señala que los imaginarios del milenio cristiano o de la sociedad comunista, por ejemplo, son imaginarios sociales; así, nos dice que éstos son modos de representación de la forma misma de la plenitud, y en este sentido, es debido a lo «fallido» de ellos mismos que la forma de la objetividad debe emanciparse de toda entidad concreta, y asumir un carácter de horizonte siempre fallido. Por lo tanto, la condición de emergencia no sería otra cosa que la condición de un imaginario colectivo como metaforización del contenido literal de ciertas reivindicaciones, y, asimismo, el horizonte imaginario en el que emerge cierta dislocación es exterior a una dislocación en cuanto tal y no puede deducirse a partir de esta última, pues entre la estructura dislocada y el discurso que intenta introducir un nuevo orden y articulación, no hay ninguna medida común. ${ }^{53}$

Laclau sostiene que el espacio mítico opera de dos formas. Por un lado, en tanto encarnación de la forma de la plenitud en cuanto tal, que transfiere metafóricamente a su contenido literal la encarnación del mito a través de la sobredeterminación que se impone y consolida en el orden social del espacio mítico; y, por otro, la sobredeterminación es al mismo tiempo fuerza y debilidad, pues sí la forma de la plenitud tiene un espacio de representación, toda demanda (entendida como una unidad mínima de análisis de las identidades colectivas) específica será referida, y toda dislocación específica encontrará la forma invertida de su expresión. Ello quiere decir que hay una inestabilidad entre la relación del espacio mítico y su función de representación de la forma general de la plenitud que no le permite dominar la representación hegemónica. Laclau insistirá en que las dinámicas del espacio mítico y del sujeto en las sociedades contemporáneas se amplían a expensas de la objetividad estructural. La dualidad del espacio mítico constituye el orden concreto y al mismo tiempo representa la forma de la plenitud del orden, permitiendo que la plenitud de lo social no se manifieste en ningún orden social concreto, sino en la posibilidad de representar su radical indeterminación. De tal modo, la indeterminación no se manifiesta a partir de la cancelación de todas las determinaciones, sino en la subversión de ellas, es decir: la afirmación de su presencia en un contexto destruye su misma posibilidad. Esto es lo que Laclau llamará, pues, «dislocación».

\footnotetext{
50 Ídem.

51 Ídem.

52 Ídem.

53 Ibíd., p. 81.
} 
A partir de lo expuesto, Laclau señalará que la fragmentación y limitación de los actores sociales (sujetos políticos), y la permanente dislocación entre imaginarios sociales y espacios míticos, permite entender que no hay lugar para la dicotomía entre base/superestructura en cualquier nivel social, porque ese lugar puede ser cualquiera de las rearticulaciones míticas o sobredeterminaciones imaginarias. De manera que la sociedad, en última instancia, es irrepresentable, y aunque toda representación sea un intento de construir la sociedad, ella no se puede reducir al espacio del momento antagónico en el cual se enfrentan dos representaciones, porque estas son pura temporalidad.

En el apartado "Tiempo, democracia y socialismo" de Nuevas reflexiones sobre la revolución de nuestro tiempo, dedicado a entrevistas a Laclau (en el que participan como entrevistadores Robin Blackburn, ${ }^{54}$ Peter Dews ${ }^{55}$ y Anna Marie Smith ${ }^{56}$ ) se le pregunta a Laclau por el sujeto constituido a través del lenguaje, como metáfora del orden establecido, y por la política entendida como una práctica de creación, reproducción y trasformación de las relaciones sociales, a lo que responde:

Yo nunca he sostenido el punto de vista de que el sujeto es construido pasivamente por las estructuras, ya que la lógica misma de la hegemonía como terreno primario de constitución de la subjetividad presupone una falta en los centros mismos de las estructuras -es decir, la imposibilidad de estas últimas de alcanzar una autoidentidad. La falta es precisamente el locus del sujeto, cuya relación con las estructuras tiene lugar a través de varios procesos de identificación (en el sentido psicoanalítico). En la teoría althusseriana de la interpelación -que he usado en mis primeros trabajos- está presente, sin duda, la noción spinoziana de un "efecto sujeto", que deriva meramente de la lógica de las estructuras. Esto deja de lado el hecho de que la interpelación es el terreno de la producción del discurso, y de que a los efectos de "producir" sujetos de modo exitoso estos últimos deben identificarse con la interpelación. El énfasis althusseriano en la interpelación como mecanismo funcional de la reproducción social no deja suficiente espacio para estudiar la construcción de sujetos desde la perspectiva de los individuos que reciben esas interpelaciones. La categoría de falta está por lo tanto ausente. Pero lo que se subraya en mis trabajos, incluso en mis primeros trabajos, es algo diferente. La interpelación es concebida como parte de un proceso hegemónico-articulatorio abierto y contingente que no puede ser confundido en ningún sentido con la "eternidad" spinoziana.

$[\ldots]$ es que las estructuras nunca pueden alcanzar la plenitud de un sistema cerrado porque el sujeto es constitutivamente falta $[\ldots]$ no es posible preguntarse quién es el agente de la hegemonía sino, por el contrario, cómo alguien pasa a ser un sujeto a través de la articulación hegemónica. ${ }^{57}$

Como hemos visto, las articulaciones hegemónicas no poseen un efecto de clausura de lo social, sino que en cierta medida de efectos «suturantes». En este sentido, el filósofo argentino afirma la relación entre la dislocación como la incapacidad de suturar definitivamente la identidad y el orden social y el sujeto como «falta». Respecto a esto, Laclau señala la relación entre la política y el sujeto:

Hablamos aquí de política, pero no porque nos refiramos a ninguna categoría regional: "Política" es una categoría ontológica: hay política porque hay subversión y dislocación de lo social. Lo cual implica que todo sujeto es, por definición, político. Aparte del sujeto, en este sentido radical, sólo hay posiciones de sujeto en el campo general de la objetividad. Pero el sujeto, en el sentido en que lo entendemos en este texto, no puede ser objetivo: él sólo se constituye en los bordes dislocados de la estructura. Explorar el campo de la emergencia del sujeto en las sociedades contemporáneas equivale, por ende,

\footnotetext{
${ }^{54}$ Historiador británico y profesor de sociología de la Universidad de Essex. Director New Left Review entre los años 1989 - 1999. 55 Profesor del Departamento de Filosofía de la Universidad de Essex y miembro del comité de redacción de New Left Review en los años 90's.

56 Alumna del Doctorado en la Universidad de Essex bajo la dirección de Ernesto Laclau en los años 90's.

${ }^{57}$ Laclau, Ernesto. Nuevas reflexiones acerca de la revolución de nuestro tiempo. Buenos Aires, Nueva Visión, 2000, pp. $219-220$.
} 
a explorar las huellas que la contingencia ha inscripto en las estructuras aparentemente objetivas de las sociedades en que vivimos. ${ }^{58}$

Para Laclau ésta es la razón por la que no hay simplemente identidad, sino más bien, identificación. Por consiguiente, podemos introducirnos en la teoría política que plantea Laclau de la decisión en torno al sujeto.

\section{Sujeto y decisión}

Tal como hemos observado, en la teoría política de Laclau hay que tener presente el rechazo a la identidad plena del sujeto, y, además la imposibilidad de lo social como totalidad fundante. Tanto la plenitud del sujeto como la estructuración completa de la sociedad son imposibles debido a la inestabilidad de la representación de carácter abierto en todo ordenamiento político y social. Así, para Laclau las nociones de sujeto, identificación y decisión nos trasladan al campo político de la constitución de identidades colectivas como «sujetos descentrados», lo que significa que hay una pluralidad de posiciones de sujeto diferenciales y antagónicas.

Laclau y Mouffe al reconstruir la categoría de hegemonía en la teoría marxista clásica, rechazan que el sujeto proletario constituya su identidad clasista como agente privilegiado de la revolución. La categoría de hegemonía se entenderá como una respuesta a la crisis del marxismo, oponiéndose al racionalismo del marxismo clásico y a la lógica de la necesidad de la historia y de la sociedad como totalidad inteligible. Es importante señalar que la teoría de hegemonía en Laclau tiene dos grandes referentes: Gramsci y Althusser. En efecto, el desarrollo conceptual de la hegemonía es en gran medida una obra del filósofo italiano, para avanzar en la comprensión de las identidades colectivas. A su vez, la noción althusseriana de sobredeterminación permitirá visualizar al argentino que no hay una literalidad última que constituya definitivamente las relaciones sociales

Los autores exponen que la crisis marxista no es sino del paradigma político esencialista del marxismo clásico, pues este sistema sólo es posible basándose en un modelo clausurado. Por lo cual, al no haber un sujeto político privilegiado, el espacio político queda abierto a la multiplicidad de identidades colectivas. En este sentido, las identidades sociales en el espacio social están en relación con la emergencia de nuevos antagonismos sociales. Según los autores: "Esta proliferación de luchas se presentan, en primer término, como un 'exceso' de lo social respecto a los cuadros racionales y organizados de la 'sociedad' esto es, del 'orden' social-". 59

Hay una imposibilidad de lo social, a partir de la propagación de diferencias en nuestra sociedad contemporánea, que implica una dificultad para las prácticas articulatorias en los discursos que se estructuran en el campo de lo social. En este sentido, Laclau y Mouffe rechazarán: “[...] el supuesto de una "sociedad" como estructura inteligible, que puede ser abarcada y dominada intelectualmente a partir de ciertas posiciones de clase y reconstruida como un orden racional y transparente de un acto fundacional de carácter político." 60

De este modo, el concepto de totalidad es rechazado para entender la dispersión actual de los conflictos en la multiplicidad de lo social, y, asimismo, señalan, no hay una «verdad» que permita conocer el significado de las prácticas de las identidades colectivas. Según los autores, como no hay una determinación de lo social, estas superficies del campo social están atravesadas por el antagonismo y la contingencia que domina a las identidades colectivas (sujetos políticos). Negada la pretensión de una posición ontológica por parte de una clase en particular, se renuncia “a toda prerrogativa epistemológica

\footnotetext{
58 Ibíd., p. 77. (el destacado es del original)

59 Laclau, Ernesto y Mouffe, Chantal. Hegemonía y estrategia socialista. Hacia una radicalización de la democracia. Buenos Aires, FCE, 2004, p. 25.

${ }^{60}$ Ibíd., p. 26.
} 
fundada en la presunta posición ontológicamente privilegiada de una clase universal" 61 del marxismo ortodoxo. En efecto, siguiendo lo que nos señalan los autores, la «totalidad de lo social» en la tradición marxista no puede seguir manteniendo un horizonte ni determinista ni esencialista de los sujetos políticos $^{62}$ (está problemática ha sido abordada con mayor profundidad en otros artículos).

La especificidad del pensamiento de Laclau respecto de las identidades colectivas está en relación con los procesos de incompletitud en la constitución de los sujetos políticos, pues estas identidades son contingentes y precarias, al igual que la sociedad, donde resulta imposible adquirir una forma de plenitud. Laclau enfatiza el carácter inconsistente de los agentes sociales; no hay un sujeto que pueda pretender una identidad plena. Vale decir, Laclau está objetando tanto la concepción del sujeto moderno centrado en el cogito cartesiano, como el devenir teleológico histórico-social de la tradición marxista.

Ahora bien, no olvidemos que Laclau en su andamiaje teórico abordará también la teoría política y social desde el psicoanálisis y la desconstrucción. Por un lado, la relación entre sujeto, identificación y decisión es desarrollada a partir del antagonismo y el Real lacaniano; y, por otro, la relación entre el sujeto como «falta» y la subjetivación como proceso de identificación/decisión respecto de las identidades colectivas. De tal modo, la política puede ser pensada como un campo de indecidibilidad ${ }^{63}$ respecto del orden social, en la que el espacio social es planteado como una estructura «fallida» de los sujetos políticos donde éstos se constituyen como tal.

Laclau sostiene que debido a que hay política, hay subversión y dislocación de lo social, lo que implica que «todo» sujeto es político, y por eso "la dislocación es la huella de la contingencia en el seno de la estructura". ${ }^{64}$ Así, toda decisión es una «decisión política».

La identidad de los sujetos políticos es el momento de la decisión contingente, y, al mismo tiempo, es el momento político que funda la objetividad. En el artículo "Desconstrucción, pragmatismo y hegemonía", Laclau desarrolla la relación entre indecidibilidad y decisión para la política. Argumenta que la estructura (orden) es indecidible porque no hay un cierre, y la decisión no se determina en última instancia por nada externo a ella. Siguiendo a Derrida, afirmar que la decisión es algo que siempre escapa a cualquier regla determinante, y que tiene que estar basada en sí misma, en su propia singularidad. ${ }^{65}$ En este sentido, Laclau concluye que la relación entre indecidibilidad y decisión no puede ser abordada sin entrar a la cuestión del sujeto, ${ }^{66}$ puesto que todo sujeto es necesariamente político. Como hemos visto, el

${ }^{61}$ Ibíd., p. 28.

${ }^{62}$ Es necesario aclarar que la categoría de hegemonía en Laclau opera a la luz de su matriz gramsciana, como voluntad colectiva. El concepto de hegemonía desarrollado por Gramsci es la piedra angular para pensar la constitución de sujetos políticos. Como lo expusimos anteriormente, Gramsci, desde una perspectiva marxista, fue quien avanzó considerablemente en la conceptualización de la hegemonía al considerar los espacios ideológicos y políticos como una dimensión fundamental para la conformación de identidades colectivas. Sin embargo, es evidente que Gramsci no pudo ir más allá, pues su teoría aún mantenía una la lógica determinista y esencialista del marxismo clásico.

63 Término desarrollado por Jacques Derrida: "Lo indecidible no es meramente la oscilación o la tensión entre dos decisiones; es la experiencia de aquello que, aunque heterogéneo, extraño al orden de lo calculable y de la regla, aún está obligado —es de obligación de lo que debemos hablar- a rendirse a la decisión imposible, a la vez que toma en cuenta la ley y las reglas. Una decisión que no pasara a través de la dura prueba de lo indecidible no sería una decisión libre, sería solamente la aplicación o el despliegue programable de un proceso calculable". Derrida, Jacques. "Force of Law: The Mystical Foundation of Authority", en: Drucilla Cornell, Michel Rosenfeld y David Gray Carlson (comps.) Desconstrution and the Possibility of Justice, Nueva York \& Londres, 1992, en: Laclau, Ernesto. “Desconstrucción, pragmatismo, hegemonía”, en: Laclau, Ernesto, Rorty, Richard, Critchley, Simon y Derrida, Jacques. Mouffe, Chantal (comp.) Desconstrucción y pragmatismo. Buenos Aires, 1998, Paidós, p. 109.

64 Ibíd., p.112.

65 Ibíd., pp. 109-110.

${ }^{66}$ En este sentido, Laclau sintetiza la relación entre indecidibilidad de la estructura y sujeto de la decisión en seis puntos: "1) toda posición de sujeto es el efecto de una determinación estructural (o de una regla, lo cual viene a ser lo mismo) -no tiene el status de una conciencia sustancial constituida fuera de la estructura-; 2) como una estructura es, no obstante, constitutivamente indecidible, se requieren decisiones que la estructura (ya sea un código legal, una configuración institucional, roles familiares, etcétera) no predetermina -éste es el momento de la emergencia del sujeto como algo diferente de las posiciones de sujeto-; 3) como la decisión que constituye al sujeto es tomada en condiciones de indecibilidad insuperable, ella no expresa la identidad del sujeto 
sujeto se define como la distancia entre la indecidibilidad de la estructura y la decisión, hay sujeto cuando esta falta originaria es positiva en cierto sentido, y lo único que puede lograr esta positividad es el momento de la decisión, y que, a su vez, es contingente. En palabras de Laclau: " [...] si la indecidibilidad reside en la estructura en cuanto tal, en ese caso la decisión que desarrolle una de sus posibilidades será contingente -es decir, externa a la estructura, en el sentido de que si bien resulta posible a partir de la estructura no está, sin embargo, determinada por ella". ${ }^{67}$

La decisión no es nunca una decisión radical, es siempre una parcial porque la estructura está fallida, aunque nunca falle completamente. Por lo cual, se es sujeto en la medida que la decisión crea la necesidad de una identificación contingente. La función ontológica del sujeto es positivizar la falta, y, asimismo, identificarse con algo que está destinado a ser una forma de plenitud. Si este es el caso, el sujeto únicamente existe atado a las experiencias de dislocación.

En Nuevas reflexiones sobre la revolución de nuestro tiempo Laclau señala que toda identidad es relacionalmente contingente respecto de sus condiciones de existencia en el orden político, donde está claro que la decisión tomada al interior de una estructura es indecidible. El autor plantea al sujeto respecto de la decisión:

[...] si por un lado el sujeto no es externo respecto de la estructura, por el otro se autonomiza parcialmente de esta en la medida en que él constituye el locus de una decisión que la estructura no determina. Pero esto significa: (a) que el sujeto no es otra cosa que esta distancia entre la estructura indecidible y la decisión; (b) que la decisión tiene, ontológicamente hablando, un carácter fundante tan primario como el de la estructura a partir de la cual es tomada, ya que no está determinada por esta última; (c) que, si la decisión tiene lugar entre indecidibles estructurales, el tomarla sólo puede significar la represión de las decisiones alternativas que no se realizan. Es decir que la "objetividad" resultante de una decisión se constituye, en su sentido más fundamental, como relación de poder. ${ }^{68}$

Hay que tener presente que Laclau sostiene que la decisión no se basa en ninguna racionalidad externa así misma, y que hay en ella una opacidad que no permite considerarla en su auto-transparencia, sino como una situación cuyo mecanismo se escapa al sujeto. Por eso el sujeto no precede a la decisión, sino que es producto de la decisión.

Vemos, así, como Laclau plantea el orden de lo político por sobre lo social, lo que tiene como consecuencia la imposibilidad de sutura de la totalidad de lo social. Sin embargo, esto apunta a la contingencia e inestabilidad del propio campo político. Tal imposibilidad radica en el exceso que subvierte la totalidad al no tener un fundamento último (inestabilidad fruto de que no hay un centro ordenador). Asimismo, lo político es planteado ontológicamente a partir de la constitución indeterminada de las identidades políticas en los conflictos, antagonismos y sujetos políticos. De modo que una sociedad reconciliada es imposible, puesto que el poder es condición de posibilidad de lo social (y al mismo tiempo es condición de imposibilidad). Para Laclau, la transformación de lo social corresponde a la construcción de un nuevo poder, no a su eliminación. De ahí la necesidad de construir identidades colectivas, a partir de la imposibilidad de una sociedad reconciliada. En este sentido, las relaciones sociales, al ser contingentes, pueden ser efectivamente trasformadas a través de las luchas sociales.

(algo que el sujeto ya es) sino que requiere actos de identificación; 4) estos actos escinden la nueva identidad del sujeto: esta identidad, por un lado, es un contenido particular; por el otro lado, encarna la completud ausente del sujeto; 5) como esta completud ausente es un objeto imposible, no hay ningún contenido que esté a priori determinado para cumplir esta función de encarnación -cuál será el objeto que privilegiará las investiduras 'catéctico-políticas' es algo que no puede ser determinado en una situación descontextualizada-; 6) como la decisión es siempre tomada dentro de un contexto concreto, lo que es decidible no es enteramente libre: lo que se considera una decisión válida tendrá los límites de una estructura que, en los hechos está sólo parcialmente desestructurada". en: Laclau, Ernesto. "Desconstrucción, pragmatismo, hegemonía", en: Laclau, Ernesto, Rorty, Richard, Critchley, Simon y Derrida, Jacques. Mouffe, Chantal (comp.) Desconstrucción y pragmatismo. Buenos Aires, 1998, Paidós, p. 119.

${ }_{67}$ Laclau, Ernesto. Nuevas reflexiones acerca de la revolución de nuestro tiempo. Buenos Aires, Nueva Visión, 2000, p. 46.

${ }^{68}$ Ibíd., p. 47. 


\section{El sujeto pueblo}

En La razón populista, se vislumbra cómo Laclau pretende problematizar lo político en torno a la lógica de formación de identidades colectivas, a partir de distintos andamiajes teóricos como el postmarxsimo, el postfundacionalismo, el postestructuralismo, el psicoanálisis, la desconstrucción, la fenomenología y la retórica. Como dijimos anteriormente, Laclau al inicio de dicho texto señala que la gran interrogante del texto será la «lógica de formación de identidades colectivas».

Antes de ingresar en la teoría laclausiana del populismo, hay que tener en consideración que su obra ha generado bastantes debates y críticas por parte de distintos investigadores y académicos. Autores como Benjamín Arditi, Sebastián Barros, Javier Balsa, Gerardo Aboy Carles, Julián Melo o Francisco Panizza ${ }^{69}$, por nombrar algunos, han problematizado y/o criticado el andamiaje teórico que Laclau expresa en dicha obra en torno a la categoría de populismo. Esta discusión ha abierto distintas posturas y recepción sobre el populismo, sin embargo, es necesario advertir que no ahondaremos en estos debates, pues esto excede las pretensiones de este artículo.

Ahora bien, según Retamozo, el status del pueblo como sujeto colectivo es primordial en la batería conceptual de Laclau. Según él, en La razón popular “[...] el punto de partida es la pluralidad de lo social; es decir, el hecho que bajo el capitalismo globalizado es cada vez más evidente la multiplicidad de posiciones, intereses o 'demandas' producto de la expansión de luchas sociales y el imaginario democrático-igualitario.” 70

En esta obra, Laclau señala que la proliferación de luchas sociales en relación a demandas es un resultado histórico y contingente, pues en la sociedad hay múltiples formas de articulación del orden social. Siguiendo a Retamozo, Laclau plantea un desafió teórico, y que a su vez, es fundamentalmente político para "[...] pensar el modo en que estas posiciones de subordinación pasan a configurarse en espacios de subjetivación y producción de antagonismos sociales.”71 En este sentido, Retamozo explícita que los elementos de la categoría de populismo versan sobre: "[...] la existencia de demandas, proceso de articulación/producción de una frontera antagónica y la presencia de un significante vacío/vaciado que opera como aglutinante de la pluralidad, como condensación de lo múltiple, como síntesis inestable de lo heterogéneo". 72

\footnotetext{
${ }^{69}$ Una de las críticas más recurrente por parte de Benjamín Arditi, Sebastián Barros Gerardo Aboy Carlés y Julián Meló es la problemática de la triple sinonimia entre las categorías de política, hegemonía y populismo entre otras. En este sentido, Aboy Carlés y Meló afirman: "que el intento de Laclau por compatibilizar todo su aparato teórico con sus ideas sobre el populismo terminó por obturar la capacidad explicativa de la noción de la hegemonía que dicha obra había establecido”, en: Meló, Julián, Aboy Carles, Gerardo. "La democracia radical y su tesoro perdido. Un itinerario intelectual de Ernesto Laclau", en: Postdata, vol. 19, núm. 2, Octubre/ 2014-Marzo/2015, p. 414. Cfr. Arditi, Benjamín. "Las insurgencias no tienen un plan, ellas son el plan: performativos políticos y mediadores evanescentes en 2011”, en: Debate Feminista, núm. 46, 2012, pp. 146-169; Barros, Sebastián. "Momentums, demos y baremos: lo popular en los análisis del populismo latinoamericano", en: Postdata, vol. 19, núm. 2, Buenos Aires, 2014, pp. 315-344. Barros, Sebastián. "Populismo, pueblo y liderazgo en América Latina", en: Colombia Internacional, núm., 82, 2015, pp. 297-302.

Aboy Carles, Gerardo, Barros, Sebastián, Meló, Julián. Las brechas del pueblo. Reflexiones sobre identidades y populismo, Buenos Aires, UNGS-UNDAV, 2013.; Aboy Carles, Gerardo. "Populismo y democracia liberal, Una tensa relación, en: Identidades, Dossier 2, año 6, 2016, pp. 5-26. Fair, Hernán. "Análisis político del discurso de Ernesto Laclau: una propuesta para la investigación social transdisciplinaria”, en: Iconos, núm. 54, 2015, pp. 197-224; Paniza, Francisco. “¿De qué hablamos cuando hablamos de populismo? ¡Más populista será tu abuela!”, en: Resco, núm. 2, 2011, pp. 15- 37; Paniza, Francisco (ed.). El populismo como espejo de la democracia. Buenos Aires, FCE, 2009; entre otros.

${ }^{70}$ Retamozo, Martin. "La teoría del populismo de Ernesto Laclau: una introducción”, en: Estudios políticos, núm. 41 (mayo-agosto), 2017, México, D. F, p. 170.

71 Ibíd., p. 171.

72 Ibíd., p. 175.
} 
Laclau a partir de la categoría de «populismo» ${ }^{73}$ pretende dar cuenta de un modo de construir lo político en torno a la conformación de identidades colectivas. En este sentido, son tres conjunto de categorías que son relevantes para comprender su enfoque teórico: 1) discurso, 2) significante vacío y hegemonía; 3) retórica. ${ }^{74}$ Así, Laclua señala: "Lo primero ha sido dividir la unidad del grupo en unidades menores que hemos denominado demandas: la unidad del grupo es, en nuestra perspectiva, el resultado de una articulación de demandas" 75 , para comprender lo que nos quiere plantear Laclau es necesario que tengamos en cuenta la noción de «discurso» ${ }^{76} \mathrm{en}$ su andamiaje teórico, pues las articulaciones de demandas se moverán bajo este presupuesto, es por ello que la demanda requiere un tipo de totalización que aglutine un reclamo al orden establecido, pero que nunca alcanza una plenitud.

En este sentido, Retamozo señala que los aportes metodológicos de la teoría populista de Laclau se pueden identificar en tres campos: "[...] la producción del orden social (lo político), las formas de política y la constitución de las identidades políticas." 77

Por lo cual, hay una imposibilidad para fijar un elemento único como demanda, pues hay distintos significantes flotantes y heterogeneidad social. En este sentido, Laclau entenderá la heterogeneidad en tres formas:

Una primera forma de heterogeneidad surge cuando, $[\ldots]$, una demanda social particular no puede ser satisfecha dentro de este sistema: la demanda excede lo que es diferencialmente representable dentro de él. Lo heterogéneo es aquello que carece de una ubicación diferencial dentro del orden simbólico (es equivalente al real lacaniano). Pero existe otro tipo de heterogeneidad que es igualmente importante: la derivada de las relaciones mutuas entre demandas insatisfechas. Ya no están unidas/separadas entre sí mediante un sistema simbólico, porque es precisamente la dislocación de ese sistema lo que las ha generado en primer lugar. Pero tampoco tiende a unirse espontáneamente entre sí porque, en lo que a su especificidad se refiere, pueden ser totalmente heterogénea. Lo que les otorga un vínculo inicial y débil es tan sólo el hecho de que todas ellas reflejan un fracaso parcial del sistema institucional. ${ }^{78}$

Tanto la lógica de la equivalencia como la diferencia son incompatibles entre sí, pero al mismo tiempo, una necesita de la otra, y viceversa, como condiciones necesarias para la construcción de lo social, provocando una tensión irreductible. Al no haber separación de las dos lógicas, la totalización en torno a la hegemonía y los significantes vacíos nos muestra lo siguiente:

Por un lado, tenemos toda identidad social (es decir, discursiva) es constituida en el punto de encuentro de la diferencia y la equivalencia, del mismo que las identidades lingüísticas constituyen la sede de relaciones sintagmáticas y de combinaciones paradigmáticas de sustitución. Sin embargo, por otro lado,

\footnotetext{
73 Abordaremos la categoría de populismo desde la obra La razón populista, sin embargo, es necesario decir que Laclau había trabajado anteriormente esta categoría en su obra Política e ideología en la teoría marxista. Capitalismo, fascismo, populismo de 1977, en el último capítulo "Hacia una teoría del populismo". Y también, en el artículo "Populismo y transformación del imaginario político de América Latina" de 1987.

${ }_{74}$ Cfr. Laclau, Ernesto. La rąón populista. Buenos Aires, FCE, 2013, p. 92-95.

75 Ibíd., p. 9.

${ }^{76}$ Laclau y Mouffe señalan: [...] "llamaremos articulación a toda práctica que establece una relación tal entre elementos, que la identidad de éstos resulta modificada como resultado de la práctica. A la totalidad estructurada resultante de la práctica articulatoria la llamaremos discurso. Llamaremos momentos a las posiciones diferenciales, en tanto aparecen articuladas al interior de un discurso. Llamaremos, por el contrario, elementos a toda diferencia que no se articula discursivamente", en: Laclau, Ernesto y Mouffe, Chantal. Hegemonía y estrategia socialista. Hacia una radicalización de la democracia, Buenos Aires, FCE, 2004 , p.123. Posteriormente, Laclau señala: "Por discurso no entendemos algo esencialmente restringido a las áreas del habla o la escritura, [...], sino como un complejo de elementos en el cual las relaciones juegan un rol constitutivo", en: Laclau, Ernesto. La razón popular. Buenos Aires, FCE, 2004, p. 92.

77 Retamozo, Martin. "La teoría política del populismo: usos y controversias en América Latina en la perspectiva posfundacional”, en: Latinoamérica. Revista de Estudios Latinoamericanos, Volume 64, 2017, p.145

${ }^{78}$ Ibíd., p. 139.
} 
existe un desnivel esencial en lo social ya que, [...], la totalización requiere que un elemento diferencial asuma la representación de una totalidad imposible. ${ }^{79}$

Es por ello, que se privilegia una determinada identidad -que proviene del campo de las diferencias- para representar esta función totalizadora. Laclau plantea que las diferencias entre una totalización populista y una institucionalista deben ser examinadas a partir de los significantes privilegiados hegemónicos, pues estos se estructuran como puntos nodales en el conjunto de la formación discursiva. Así, ningún contenido particular tiene una inscripción óntica por su especificidad en una formación discursiva, sino que dependerá del sistema de articulaciones diferenciales y equivalenciales dentro del cual están situados. En este sentido, Laclau nos dirá que "la posición del sujeto popular no expresa simplemente una unidad de demandas constituidas fuera y antes de sí mismo, sino que es el momento decisivo en el establecimiento de la unidad". ${ }^{80}$

La tesis de Laclau sobre la categoría de populismo radica en que, por un lado, el requerimiento para el surgimiento del pueblo es a partir de demandas aisladas y heterogéneas, que puedan entrelazarse en una lógica equivalencial, y por ende, pasan a ser una demanda global, implicando la formación de fronteras políticas y la construcción discursiva del poder como fuerza antagónica. Y por otro lado, interviene la dimensión afectiva en torno a la nominación, según Laclau: "Este momento cualitativamente diferenciado es lo que hemos denominado 'investidura radical"'. ${ }^{81}$ En este sentido, la investidura pertenecerá necesariamente al afecto, y por ende, a una relación más íntima entre significación y afecto. El polo paradigmático del lenguaje -el polo asociativo de Ferdinand de Sausarre- constituirá una parte integra del funcionamiento del lenguaje. Sin embargo, para Laclau las relaciones paradigmáticas están dominadas por el insconciente y se constituyen en sustituciones que operarán a nivel del significante, y a su vez, en el significado. Laclau señala:

El afecto no es algo que exista por sí solo, independiente del lenguaje, sino que sólo se constituye a través de la catexia diferencial de una cadena se significación. Esto es exactamente lo que significa investidura. La conclusión es clara: los complejos que denominamos 'formaciones discursivas o hegemónicas', que articulan las lógicas de diferencia y equivalencia, serían inteligible sin el componente del afecto. ${ }^{82}$

Por lo tanto, cualquier totalidad social será el resultado de una articulación indisociable entre la dimensión de significación y afecto. En este sentido, Laclau nos dirá:

[...] el nombre se convierte en el fundamento de la cosa. Un conjunto de elementos heterogéneos mantenidos equivalencialmente unidos sólo mediante un nombre es, sin embargo, necesariamente una singularidad. Una sociedad, cuanto menos se mantiene unida por mecanismo diferenciales inmanentes, más depende, para su coherencia, de este momento trascendente, singular. Pero la forma extrema de singularidad es individualidad. De esta manera casi imperceptible, la lógica de la equivalencia conduce a la singularidad, y ésta a la identificación de la unidad del grupo con el nombre del líder. ${ }^{83}$

De este modo, Laclau plantea que la categoría de populismo no debe asociarse a la idea como manipulación o sugestión, porque para él una formación hegemónica es ininteligible sin una dimensión afectiva. Así, una relación hegemónica será aquella determinada particularidad que asume una universalidad imposible, pues la aspiración de la totalidad es transferida a objetos parciales. De este modo,

\footnotetext{
${ }^{79}$ Ibíd., p. 107.

80 Ibíd., p, 129.

81 Ibíd., p. 142.

82 Ibíd., p. 143.

${ }^{83}$ Ibíd., p. 130.
} 
no existe ninguna universalidad que no sea una universalidad hegemónica. Por lo cual, no habrá populismo sin una investidura efectiva de un objeto parcial. En sus palabras:

El objeto de la investidura puede ser contingente, pero ciertamente no es indiferente, no puede ser cambiado a voluntad. Con esto logramos una explicación completa de lo que significa investidura radical: el hacer de un objeto la encarnación de una plenitud mítica. El afecto (es decir, el goce) constituye la esencia misma de la investidura, mientras que su carácter contingente da cuenta del componente radical de la formula. ${ }^{84}$

Así, no existirá ninguna totalidad social alcanzable sino es a través de la hegemonía, vale decir, la hegemonía es la investidura, el objeto parcial de una totalidad que siempre nos va a evadir porque es mítica. Laclau enfatiza "[...] la lógica del objeto a y la lógica hegemónica no son similares: son simplemente idénticas". ${ }^{85} \mathrm{La}$ única plenitud posible es a través de una parcialidad que encarna la representación de una plenitud mítica. Es evidente, la importancia de una lógica hegemónica en este punto, pues un particular asume una función universal, sin perder su condición de particular. Por tanto, es precisamente aquí donde se puede producir una operación de subjetivación o interpelación populista.

Cuando una demanda puede tomar la centralidad de un discurso, es capaz de representar la heterogeneidad de éstas. La lógica política del populismo será la condición de la construcción de «pueblo» como agente histórico y como sujeto político, sin embargo, Laclau plantea que hay una tensión en el orden social que impide que todos los habitantes de un territorio se comprendan como un pueblo. El filósofo argentino lo expresará a partir de la etimología latina: plebs y populus, vale decir, una plebs que reivindica ser un populus. Laclau señala que "la posición del sujeto popular no expresa simplemente una unidad de demandas constituidas fuera y antes de sí mismo, sino que es el momento decisivo en el establecimiento de esta unidad"86. Este elemento unificador nunca es neutral o transparente, pues la potencia plebeya es capaz de cuestionar lo instituido y abrir espacios instituyentes que incluyen procesos constituyentes y, por tanto, nuevas constituciones políticas de Estado.

A partir de lo expuesto, Laclau señala que debemos entender el «populismo» como una lógica política que están en relación a la institución de lo social. Éste no comprende una institución como mandato arbitrario, sino que surge de las demandas sociales, y ese sentido, inherente a cualquier cambio social. Dicho cambio se ubica en la articulación variable de la lógica de la equivalencia y la diferencia, es decir: [...] el momento equivalencial presupone la constitución de un sujeto político global que reúne una pluralidad de demandas sociales. Esto, a su vez, implica, “[...] la construcción de fronteras internas y la identificación de un 'otro' institucionalizado". 87 En este sentido, la heterogeneidad no significaría diferencialidad, pues no puede existir un sistema de unidad presupuestado. Laclau señala que esto tiene dos consecuencias:

(a) el momento de unidad de sujetos populares se da a nivel nominal y no en nivel conceptual -es decir, los sujetos populares siempre son singularidades-; (b) precisamente porque es nombre no está conceptualmente (sectorialmente) fundamentado, los límites entre las demandas que van a abarcar y aquellas que se va a excluir se van a desdibujar y van a dar lugar a un cuestionamiento permanente. A partir de esto podemos deducir de un lenguaje populista -ya sea de izquierda o de derecha- siempre va a ser impreciso y fluctuante: no por alguna falla cognitiva, sino porque intenta operar perfomativamente dentro de una realidad social que es en gran medida heterogénea y fluctuante. ${ }^{88}$

\footnotetext{
${ }^{84}$ Ibíd., p. 148

85 Ibíd., p. 148-49.

86 Ibíd., p. 129.

87 Ibíd., p. $150-51$.

${ }^{88}$ Ibíd., p. 151
} 
Así, Laclau plantea que una determinada demanda, que quizás en un principio era sólo una demanda más de la pluralidad de demandas, adquiere un cierto rol de centralidad y se vuelve un significante vacío, que encarna una representación de una totalidad imposible. Por consiguiente, estas lógicas estarán en una constante tensión, pues una cadena equivalencial puede debilitar el particularismo de sus eslabones. Sin embargo, esto no significaría que se pueda deshacer del particularismo.

De este modo, para analizar la noción de «pueblo» como categoría política es necesario entenderlo como un acto de institución que instaura un nuevo agente a partir de la multiplicidad de elementos heterogéneos. Laclau insiste que la "[...] unidad de análisis mínima no sería el grupo, como referente, sino la demanda sociopolítica". ${ }^{99}$ Por ello, señala que para pensar la categoría de pueblo es necesario tener presente la heterogeneidad social. Nuestro autor expone que la heterogeneidad es primordial e irreductible en última instancia a toda homogeneidad, y por ende, se mostrará a sí misma como exceso, es decir, "[...] la heterogeneidad, [...], [esta] en una dimensión de ser deficiente o unicidad fallida" 90 . En este sentido, la forma fenoménica de la presencia/ausencia establece que diversos elementos heterogéneos están sobredeteminados o investidos diferencialmente, y en la cual, se requiere una construcción social contingente (articulación y hegemonía).

Según Laclau el pueblo como actor histórico tiene la peculiaridad de la universalidad del populus y la parcialidad de la plebs, lo que denominará como «razón populista», vale decir, la lógica de construcción de formaciones de identidades colectivas. La demanda popular representa la plenitud ausente de la comunidad por medio de una cadena equivalencial potencialmente indeterminable. Cuando se alcanza la inversión de la relación parte/todo, la relación populus/plebs se transforma en una tensión en la que cada término captura, y a su vez, expulsa al otro. Esto significa que la tensión nunca logra una reconciliación de las partes, por ende, no existe ninguna parcialidad que no contenga a su vez huellas de lo universal. En otras palabras, Laclau nos dice: [...] la lógica del objeto a, es decir, la posibilidad de que una parcialidad se convierta en el nombre de una totalidad imposible"

Por un lado, Laclau establece a partir de la relación entre nominación y contingencia, las identidades colectivas son el resultado de una pluralidad de demandas sociales que se unifican por la lógica de equivalencia de contigüidad. Donde la nominación será el momento clave en la constitución de pueblo, pues tanto sus límites como componentes equivalenciales fluctúan permanentemente. Por otro lado, según Laclau, aquí radica la importancia del rol afectivo en torno a las identidades populares. En sus palabras:

El lazo afectivo se vuelve más importante cuando la dimensión combinatoria/simbólica del lenguaje opera de manera menos automática. Desde esta perspectiva, el afecto es absolutamente crucial para explicar el funcionamiento del polo sustitutivo/paradigmático del lenguaje, que es el de asociación libre en su funcionamiento (y, por esta razón, el más abierto a la exploración psicoanalítica). La lógica equivalencial, [...], es decisiva en la formación de identidades populares, y en estas operaciones sustitutivas/ equivalenciales, la imbricación entre significación y afecto se muestra más cabalmente. ${ }^{92}$

Laclau señala que para entender la emergencia del pueblo como actor histórico es necesario tener presente el momento equivalencial/articulador surge de una necesidad lógica, en la cual la demanda se enlaza con otras, pues la nueva unificación de demandas dentro de esta pluralidad es constitutiva, y por ende, no derivativa. El filósofo argentino señala:

La emergencia del pueblo depende de tres variables, [...]: relaciones equivalenciales representadas hegemónicamente a través de significantes vacíos; desplazamientos de las fronteras internas a través

\footnotetext{
${ }^{89}$ Ibíd., p. 278

90 Ibíd., p. 277

91 Ibíd., p. 281

92 Ibíd., p. 282-83
} 
de la producción de significantes flotantes; y una heterogeneidad constitutiva que hace imposibles las recuperaciones dialécticas y otorga su verdadera centralidad a la articulación política. ${ }^{93}$

La emergencia del pueblo como actor histórico será una transgresión respecto a una situación anterior. En este sentido, Laclau plantea que las condiciones históricas que hacen posible la emergencia y expansión de las identidades populares es la condición estructural, es decir: "[...] la multiplicación de demandas sociales cuya heterogeneidad sólo puede ser conducida a cierta forma de unidad a través de articulaciones políticas equivalenciales." 94 A partir de esto, podemos comprender que Laclau presenta una respuesta estructural de las lógicas de formación de identidades colectivas/populares, donde las fronteras antagónicas se constituyen en lógicas equivalenciales, por ende, las fronteras son una condición necesaria para la emergencia del pueblo, pues sin las fronteras no podría haber dialéctica entre parcialidad/universalidad. De este modo, entre más extensa sea la cadena equivalencial, es más difícil determinar la identificación del enemigo en la multiplicidad de demandas heterogenias, es decir, aquello que está del otro lado de la frontera. Asimismo, permitirá una multiplicación de efectos dislocatorios y nuevos antagonismos.

Finalmente, Laclau plantea que la cuestión de lo político en torno a la lógica de formación de identidades populares está vinculado a la articulación contingente -es decir, la dialéctica entre la lógica diferencial y equivalencial- y a los antagonismos. Por consiguiente, toda demanda presupone una heterogeneidad constitutiva, que conlleva un contenido particular, sin embargo, estará altamente sobredeterminada desde el principio. En palabras de nuestro autor: "[...] no existen sujetos puros del cambio; siempre están sobredeterminados por las lógicas equivalenciales. Esto implica que los sujetos políticos siempre son, de una manera u otra, sujetos populares". 95

\section{A modo de cierre}

Habiendo llegado a este punto, podemos esbozar algunas conclusiones a partir del trayecto recorrido. La cuestión de la lógica de la formación de identidades colectivas siempre ocupo un lugar central en la teoría política de Laclau. La noción de sujeto político que hemos analizado mediante el andamiaje teórico laclausiano, ha problematizado la disputa por el orden social en gran parte de su obra, por ende, los sujetos políticos son agentes capaces de tensionar el orden y construir soberanía popular.

En este sentido, la constitución de sujetos políticos se relaciona directamente con la reproducción del orden social y, con Laclau, apuntan hacia un análisis de trasformación social, pasando de la subjetividad colectiva a la constitución de sujetos políticos.

El itinerario que hemos trazado de la categoría de sujeto político en la filosofía de Laclau, supone aperturas analíticas para pensar la política, a partir del carácter discursivo de la construcción de las identidades políticas. De este modo, al situar la obra de Laclau en el horizonte post-fundacional, podemos pensar la posibilidad de considerar la teoría política en torno a la categoría de sujeto como una herramienta analítica que nos permite pensar la constitución de sujetos populares. La teoría de Laclau puede integrarse a distintos campos de la investigación y reflexión política, a partir de la heterogeneidad de sus elementos, y la novedad que les imprime.

Desde nuestra perspectiva, consideramos la trayectoria de la categoría laclausiana como una herramienta sólida y eficaz para analizar el difícil campo de la teoría política contemporánea. Elaborada a partir de distintitos paradigmas metodológicos como el marxismo, el postestructuralismo, la desconstrucción, el psicoanálisis, la fenomenología, la retórica y el postmarxismo.

93 Ibíd., p. 197.

94 Ibíd., p. 285

95 Ibíd., p. 288 
La sociedad como totalidad imposible no es sino un conjunto de relaciones articuladas de forma precaria y contingente que no tienen ningún fundamento originario. Esta incompletitud, tanto en la lógica del sujeto como en la del orden, es la que apunta a la imposibilidad de una identidad plena. Ahora bien, el sujeto político, al abandonar la representación de la particularidad, será entendido como una identidad que no alcanza la plenitud. Esto se relaciona, específicamente, con el sujeto como falta, donde es posible la emergencia de la subjetividad desde la presencia de la ausencia. Tanto la incompletitud del sujeto como de la estructura, posibilitan la fisura del orden social, y, por ende, la imposibilidad del cierre de la estructura son dimensiones para pensar la constitución de sujetos políticos.

Las identidades de los sujetos y los elementos sociales estarán constituidos discursivamente y, por ende, contingentemente. Como tal, será la estructura abierta de la sociedad lo que permitirá la constitución de sujetos políticos a través de prácticas articulatorias hegemónicas, pero que, a su vez, estarán atravesados por diversos antagonismos. Para ello, es necesario tener presente la noción de demanda como unidad mínima de análisis para pensar en la constitución de sujeto político como pueblo, debido a que mediante la pluralidad de diferentes demandas parciales entre sí, se establecerá una cadena equivalencial en torno a una oposición de fronteras antagónicas. Así, una articulación hegemónica por medio de la cadena equivalencial, encarna un rol central dentro de las distintas demandas que están alrededor de ésta, es decir, una formación hegemónica asume la representación del universal, sin embargo, nunca logra una plenitud totalizadora.

\section{Bibliografía}

Aboy Carles, Gerardo, Barros, Sebastián, Meló, Julián. "Las brechas del pueblo”, en: Reflexiones sobre identidades y populismo, Buenos Aires, UNGS-UNDAV, 2013.

Aboy Carles, Gerardo. "Populismo y democracia liberal, Una tensa relación, en: Identidades, Dossier 2, año 6, 2016, pp. 5-26.

Acha, Omar. "Del populismo marxista al postmarxista: la trayectoria de Ernesto Laclau en la izquierda nacional (1963-2013)", en: Archivos de bistoria del movimiento obrero y la izquierda, núm. 3, 2013, pp. 57-78.

Alemán, Jorge. Para una izquierda lacaniana... Intervenciones y textos. Buenos Aires, Grama, 2009.

Allevi, José. "Subjetividades, lo político y la política: Derivas de una discusión teórica", Revista Athenea Digital, vol.15, núm. 3, 2015, pp. 149-172.

Altomare, Marcelo. "Orden social y sujeto político en la teoría política de Ernesto Laclau", Postdata, núm. 12, agosto, 2007, pp. 59-73.

Arditi, Benjamín. "Post-hegemonía: la política fuera del paradigma postmarxista habitual", en: Caito, Heriberto y Franzé, Javier. Política y cultura. Madrid, Biblioteca Nueva, 2010, pp. 159-193.

Arditi, Benjamín. "Las insurgencias no tienen un plan, ellas son el plan: performativos políticos y mediadores evanescentes en 2011", en Debate Feminista, núm. 46, 2012, pp. 146-169.

Balsa, Javier, "Aspectos discursivos de la construcción de la hegemonía", Identidades, n. 1, año 1, diciembre 2011, pp. 69-90.

Barros, Sebastián. "Momentums, demos y baremos: lo popular en los análisis del populismo latinoamericano", en: Postdata, vol. 19, núm. 2, Buenos Aires, 2014, pp. 315-344.

82, 2015, pp. 297-302.

"Populismo, pueblo y liderazgo en América Latina", en: Colombia Internacional, num,

Borón, Atilio. “¿Posmarxismo? Crisis, recomposición o liquidación del marxismo en la obra de Ernesto Laclau”, en: Revista Mexicana de Sociología, México, vol. 58, núm. 1, 1996, pp. 17-42.

Biglieri, Paula y Perelló, Gloria. Los usos del psicoanálisis en la teoría de la hegemonía de Ernesto Laclau. Buenos Aires, Grama, 2012. 
"Sujeto y populismo o radicalidad del pueblo en la teoría posmarxista", Debates y Combates. Edición Homenaje a Ernesto Laclau, año 5, vol. 1, Buenos Aires, 2015, pp. 53-64.

Butler, Judith, Laclau, Ernesto y Žižek, Slavoj Contingencia, hegemonía, universalidad. Diálogos contempéranos en la izquierda. Buenos Aires, FCE, 2003.

Derrida, Jacques. "Firma, acontecimiento, contexto", en: Márgenes de la filosofía. Madrid, Cátedra, 2003.

Errejón, Íñigo y Mouffe, Chantal. Construirpueblo; hegemonía y radicalización de la democracia, Madrid, Icaria, 2015.

Fair, Hernán. "Análisis político del discurso de Ernesto Laclau: una propuesta para la investigación social transdisciplinaria", en: Iconos, núm. 54, 2015, pp. 197-224.

Farrán, Roque. "El concepto de sujeto político. Lo real, lo parcial, el no-todo y la retroacción en Žižek, Laclau y Badiou”, International Journal of Žižek Studies, vol. 5, núm. 1, 2011.

Foucault, Michel. La arqueologia del saber. Buenos Aires, Siglo XXI, 2015

Geras, Norman. "Postmarxism?”, en: New LeftReview, 163, mayo-junio, 1987.

Groppo, Alejandro. "Tres versiones contemporáneas de la comunidad: Hacia una teoría política postfundacionalista”, en: Revista de Filosofía y Teoría Política, núm. 42, 2011, pp. 49-68.

Glynos, Jason y Stavrakakis, Yannis. "Encuentros del tipo real. Indagando los límites de la adopción de Lacan por parte de Laclau", en: Critchley y Marchart (comp). Laclau. Aproximaciones críticas a su obra. Buenos Aires, Fondo de Cultura Económica, 2008, pp. 249-269.

Merlín, Nora. "Política y psicoanálisis: populismo y democracia", Topía, marzo de 2014.

Howarth, David. "Hegemonía, subjetividad política y democracia radical", en: Critchley y Marchart (comp). Laclau. Aproximaciones críticas a su obra. Buenos Aires, Fondo de Cultura Económica, 2008pp. 317347.

Lacan, Jacques. Escritos. Tomo I, Buenos Aires, Siglo XXI, 1985.

Laclau, Ernesto. Política e ideología en la teoría marxista. Capitalismo, fascismo, populismo. Madrid, Siglo XXI, 1978.

."Tesis acerca de la forma hegemónica de la política”, en: Labastida, Julio (coord.) Hegemonía y alternativas políticas en América Latina. México. Siglo XXI, 1985

. "Populismo y transformación del imaginario político en America Latina", en: Boletín de Estudios Latinoamericanos y del Caribe, núm. 42, 1987, pp. 25-38.

. Emancipación y diferencia. Buenos Aires, Ariel, 1996.

. "Deconstrucción, pragmatismo y hegemonía", en: Deconstrucción y pragmatismo, Mouffe, Chantal. (comp.). Buenos Aires: Paidós, 1998., pp. 97-136.

. Nuevas reflexiones acerca de la revolución de nuestro tiempo. Buenos Aires, Nueva

Visión, 2000.

"Identidad y hegemonía: el rol de la universalidad en la construcción de lógicas políticas", en: Butler, Judith, Laclau, Ernesto y Žižek, Slavoj Contingencia, hegemonía, universalidad. Diálogos contempéranos en la izquierda. Buenos Aires: Fondo de cultura económica, 2003, pp.49-94.

. "Construyendo universalidad", Butler, Judith, Laclau, Ernesto y Žižek, Slavoj Contingencia, hegemonía, universalidad. Diálogos contempéranos en la izquierda. Buenos Aires: Fondo de cultura económica, 2003, pp. 281-306.

."Laclau en debate: postmarxismo, populismo, multitud y acontecimiento", en: Revista de Ciencia Política, vol. 29, núm. 3, 2009, pp. 815-828.

sept, 2012, pp.127-144.

"Post-marxismo, discurso y populismo". Mauro Cerbino, en: Íconos, núm. 44, Quito, 2014, pp. 99-127.

"Política de la retórica" Los fundamentos retóricos de la sociedad. Buenos Aires, FCE, 
Laclau, Ernesto y Mouffe, Chantal. Hegemonía y estrategia socialista. Hacia una radicalización de la democracia. Buenos Aires, FCE, 2004.

Laplanche, Jean y Pontalis, Jean-Bertrand. Diccionario de psicoanálisis. Buenos Aires, Paidós, 2004.

Marchart, Oliver. El pensamiento político posfundacional: la diferencia política en Nancy, Lefort, Badiou y Laclau. Buenos Aires, FCE, 2009.

Méndez, Agustín, "La teoría de la hegemonía, una lectura desde el psicoanálisis y la deconstrucción", Utopía y praxis latinoamericana, año 19, n. 64, 2014, pp. 51-66.

Meló, Julian, Aboy Carles, Gerardo. "La democracia radical y su tesoro perdido. Un itinerario intelectual de Ernesto Laclau”, en: Postdata, vol. 19, núm. 2, Octubre/ 2014-Marzo/2015, pp. 395-427. Mouffe, Chantal. El retorno de lo político. Barcelona, Paidós, 1999.

. (comp.) Desconstrucción y pragmatismo. Buenos Aires, Paidós, 1998.

La paradoja democrática. Barcelona, Gedisa, 2003.

En torno a lo politico. Buenos Aires, Fondo de Cultura Económica, 2011.

Palti, Elías. "El retorno del sujeto. Subjetividad, historia y contingencia en el pensamiento moderno", Prismas. Revista de historial intelectual, núm. 7, 2003, pp. 27-50.

Paniza, Francisco (ed.). El populismo como espejo de la democracia. Buenos Aires, FCE, 2009.

. “De qué hablamos cuando hablamos de populismo? ¡Más populista será tu abuela!”’, en: Resco, núm. 2, 2011, pp. 15- 37.

Quiroga, María Virginia, "Discursos y sujetos. Algunos nexos y tensiones entre las perspectivas teóricas de Michel Foucault y Ernesto Laclau", Estudios políticos, 45, Instituto de Estudios Políticos, Universidad de Antioquia, pp. 79-94.

Retamozo, Martín. "Lo político y la política: los sujetos políticos, conformación y disputa por el orden social”, Revista Mexicana de Ciencias Politicas y Sociales, vol. LI, núm. 206, mayo-agosto, 2009, pp. 69-91.

. "Sujetos políticos: decisión y subjetividad en perspectiva posfundacional", Ideas

y Valores, vol. LX, núm. 147, diciembre, 2011, pp. 51-64.

. "Tras la huella de Hegemón. Usos de hegemonía den la teoría política de Ernesto

Laclau”, Revista Internacional de Filosofía Iberoamérica y Teoría Social, Año 16. N55, 2011, pp. 39-57.

"Populismo en América Latina: desde la teoría hacia el análisis político. Discurso,

sujeto e inclusión en el caso argentino", Revista Colombia Internacional, Universidad de Los Andes de Colombia, núm, 82, sept- dic, 2014, pp. 221-258.

"La teoría política del populismo: usos y controversias en América Latina en la

perspectiva posfundacional”, Latinoamérica. Revista de Estudios Latinoamericanos, Volume 64, 2017, pp.

125-151.

"Laclau y la dialéctica. Notas sobre un desencuentro con Hegel (y con Marx)", Izquierdas, 36, noviembre 2017, pp. 278-295.

Retamozo, Martín y Fernández, Mariano. "Discurso político e identidades políticas: producción, articulación y recepción en las obras de Eliseo Verón y Ernesto Laclau", Cuadernos de H Ideas, vol. 4, núm. 4, diciembre, 2010.

Retamozo, Martín y Stoessel, Soledad. "El concepto de antagonismo en la teoría política contemporánea", Estudios Políticos, 44, Instituto de Estudios Políticos, Universidad de Antioquia, 2014, pp. 13-34.

Rush, Alan. "Marxismo y Posmarxismo. Polémica Laclau-Mouffe/Geras", Revista Herramienta, núm. 18, 2001.

Stoessel, Soledad. "Las categorías de hegemonía, antagonismo y populismo en la teoría política contemporánea. Una aproximación desde la obra post-marxista de Ernesto Laclau", Revista Internacional de Filosofía Iberoamérica y Teoría Social, Año 19. Nº4, 2014, pp. 13-31.

Valdés Castillo, J. Camilo. "Hegemonía: aproximación a la constitución de sujetos políticos en Laclau", Revista Internacional de Filosofía Mutantis Mutadis, año 5, núm. 9, diciembre, 2017, pp. 51-82. 
"La categoría de hegemonía: antecedentes desde la tradición marxista hasta el postmarxismo de Laclau y Mouffe", Revista Otro siglo, Vol. 1, N¹, Julio 2017, pp. 28 - 50.

Veltemeyer, Henry. "El proyecto postmarxista: aporte y crítica a Ernesto Laclau", Revista Theomai. Estudios sobre sociedad, naturaleza y desarrollo, núm. 14, 2006, pp. 1-15.

Žižek, Slavoj. "Más allá del análisis del discurso", en: LACLAU, Ernesto. Nuevas reflexiones sobre la revolución de nuestro tiempo. Buenos Aires, Nueva Visión, 2000.

El espinoso sujeto. El centro ausente de la ontología política. Barcelona, Paidós, 2001.

. El sublime objeto de la ideología. Buenos Aires, Siglo XXI, 2003. 